\title{
Voz y quebranto. Teodora Álvarez, esclavizada y fugitiva, en la cultura jurisdiccional en el Río de la Plata (1758)
}

Voice and Sorrow. Teodora Álvarez, Enslaved and Fugitive, in the Jurisdictional Culture of the Río de la Plata (1758)

Voix et chagrin. Teodora Álvarez, esclave et fugitive, dans la culture juridictionelle du Río de la Plata (1758)

\section{Miriam Moriconi}

\section{OpenEdition}

Journals

Edición electrónica

URL: https://journals.openedition.org/rhj/4117

DOI: $10.4000 /$ rhj. 4117

ISSN: 0719-4153

Editor

ACTO Editores Ltda

Referencia electrónica

Miriam Moriconi, «Voz y quebranto. Teodora Álvarez, esclavizada y fugitiva, en la cultura jurisdiccional en el Río de la Plata (1758)», Revista Historia y Justicia [En línea], 11 | 2018, Publicado el 18 octobre 2018, consultado el 28 juin 2022. URL: http://journals.openedition.org/rhj/4117 ; DOI: https://doi.org/ $10.4000 /$ rhj. 4117

Este documento fue generado automáticamente el 29 septiembre 2020

Revista Historia y Justicia 


\section{Voz y quebranto. Teodora Álvarez, esclavizada y fugitiva, en la cultura jurisdiccional en el Río de la Plata (1758)}

Voice and Sorrow. Teodora Álvarez, Enslaved and Fugitive, in the Jurisdictional Culture of the Río de la Plata (1758)

Voix et chagrin. Teodora Álvarez, esclave et fugitive, dans la culture juridictionelle du Río de la Plata (1758)

\section{Miriam Moriconi}

\section{NOTA DEL EDITOR}

Recibido: 08 de julio de 2018 / Aceptado: 30 de septiembre de 2018

QUEBRANTAR. Metaphoricamente vale violar alguna ley, palabra o obligación.

Latín. Transgredi. Violare. Rumpere.

SAAV. Empr. 22. Quien se atrevería a quebrantar las leyes, si siempre temiesse

que le podría suceder tal cosa?

Diccionario de Autoridades, 1737

\section{Introducción}

1 La definición del epígrafe esclarece algunos de los significados de la expresión elegida para el título del trabajo y, principalmente, introduce algunas cuestiones referidas a la noción de ley y a las relaciones que puedan haberse establecido con las leyes en el 
horizonte de la cultura jurisdiccional a la que remite este análisis. Del estado actual de los conocimientos sobre el tema se desprende que, en las condiciones específicas de Antiguo Régimen el concepto de ley y su uso diferían del que adquirió bajo la concepción jurídica liberal. Sus significados y su semántica definieron un orden jurídico, pero sobre todo caracterizaron a unas comunidades europeas y coloniales en las que el Derecho y la justicia no eran legalistas ${ }^{1}$ : no se contemplaba el monopolio de la creación y gestión de la ley, las leyes no eran la expresión de la voluntad general, ni aplicables a "todos" por igual ${ }^{2} \mathrm{Y}$ aunque al hacer justicia, efectivamente, las utilizaran, no es del todo correcto considerar que los jueces "aplicaran" las leyes ${ }^{3}$. Las "leyes reales", con ser las principales, no eran exclusiva emanación de la voluntad del Soberano, ni eran excluyentes de otras fuentes normativas más o menos formales. En el siglo XVIII, como ha observado Bartolomé Clavero, se legisló desde la jurisdicción real con una "abundancia antes impensable", ya que además del propio rey, lo hicieron sus secretarios, sus ministros y los Consejos "a golpe de expedientes consultivos y disposiciones imperativas con éxitos siempre parciales", ya que las jurisdicciones subsistentes -sobre todo las eclesiásticas- o tomaban "sus propias iniciativas discordantes" o se dejaban guiar "por la inercia de un orden tradicional, frente a este

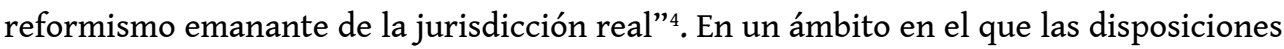
regias se repetían y modificaban constantemente, acumulando leyes y normas sin orden ni medida, como señala el mismo Clavero, se plantearon las "lógicas dificultades de su conocimiento y manejo" estar sometida a la ley. Por el contrario, los jueces destacaban en su rol de jurisprudentes ${ }^{6}$ y la alegación de privilegios personales o territoriales podía paralizar la vigencia de una ley ${ }^{7}$. Pero hasta tanto se invocasen aquellos privilegios, quien sea que perteneciera al segmento social privilegiado podía ser acusado de quebrantar las leyes. Lo mismo, aunque no con idéntico resguardo y consecuencias, sucedía a quienes carecían de privilegios y de la consideración jurídica de persona ${ }^{8}$ : podían quebrantar las leyes e invocar "derechos" a su favor.

2 Las voces y quebrantos objeto de este artículo no solamente discurren en un territorio colonial de la Monarquía Hispánica donde la instauración de una concepción legalista del derecho se registró tardíamente ${ }^{9}$, sino que, además, surgen de un grupo cuyas vinculaciones con el Derecho acusan uno de los aspectos más retardatarios de la paradigmática Declaración de Derechos del Hombre y del Ciudadano de 1789: la exclusión de las mujeres y sirvientes domésticos de ese "todos" revolucionario declamado en la noción de ciudadanía y alcance del Derecho ${ }^{10}$. Aquí el foco está puesto en las mujeres de estatuto servil cuyas condiciones tampoco fueron mejores en las Constituciones y regímenes legales de los siglos XIX y XX.

3 Mujeres en condición servil -no libres- en el Río de la Plata colonial eran las mujeres negras esclavizadas. Aunque no su estricta cantidad, ni su exacto peso demográfico, su presencia indubitable aparece en los archivos parroquiales y judiciales ${ }^{11}$. Estos últimos, al tiempo que documentan el trato que recibieron en la justicia, permiten acceder a una de las facetas menos atendidas de la cultura jurisdiccional del Río de la Plata en el siglo XVIII.

4 La cultura jurisdiccional, expresiva de la imbricación de este territorio en el orden jurídico-político católico patriarcal de la Monarquía Hispánica, también se caracterizó por una justicia de jueces ${ }^{12}$, mayoritariamente legos, y por la asidua concurrencia de las $\mathrm{y}$ los subalternos a la justicia ${ }^{13}$. En este territorio meridional, diversos jueces con 
competencias jurisdiccionales seculares o eclesiásticas, especiales $\mathrm{u}$ ordinaria, convergieron en la resolución casuística ${ }^{14}$ de conflictos en unas comunidades en las cuales no había madurado la categoría de individuo como sujeto de derecho. La condición colonial agravó la desigual antropología jurídica que ordenaba el conjunto de mujeres y varones súbditos y vasallos de la monarquía, nutriendo los grupos humanos no alcanzados por la condición jurídica de persona. Esta condición, que suponía la capacidad de titularidad y ejercicio de derechos, se adquiría conforme a la posición social que entonces refería al status y calidad clasificados por la teología y la jurisprudencia ${ }^{15}$.

5 Para terminar de puntear los aspectos básicos del horizonte de la cultura jurisdiccional a la que remite este análisis: no es que no había leyes, sino que estas eran parte de un vasto universo normativo al que acudían los jueces que actuaban igualmente impetrados por la ley positiva, las directrices del ius commune y la teología moral ${ }^{16}$. De allí que, quienes padecieron la degradación o la negación de su condición de persona ${ }^{17}$ (mujeres y, mujeres y varones, indios, negros, mestizos y castas) podían quebrantar las leyes $\mathrm{y}$, al mismo tiempo, hacer oír su voz en algún foro para invocar "derechos" a su favor; sin que ello, en especial para las mujeres, comportase titularidad o capacidad de ejercicio de derecho. Transgredir una ley -según reza la hipotética situación planteada en el epígrafe- tampoco suponía la actuación de una sola competencia jurisdiccional, ni quedar a disposición de un único juez competente, ni que los jueces tuvieran una sola manera de razonar los juicios. Por otra parte, quienes quebrantaban las leyes no eran pasibles de las mismas penas y castigos, aun cuando cometieran idéntico delito ${ }^{18}$.

6 Este artículo aborda dos cuestiones específicas referidas a esa cultura jurisdiccional. Una está relacionada con una observación que surge de los archivos eclesiásticos que registran, además de una dinámica producción normativa a nivel diocesano que nutría el universo de fuentes de derecho, una agitada actividad judicial ${ }^{19} \mathrm{y}$, en especial, la concurrencia de las mujeres ${ }^{20}$, entre las cuales se cuentan las mujeres esclavizadas. La segunda, de carácter teórico y general, reside en la exploración de dos espacios conceptuales $^{21}$, no siempre conectados, como son los derivados de los estudios sobre cultura jurisdiccional y los estudios de género, señalando particularmente el desafío de considerar aquellas contribuciones más atentas a las inflexiones raciales ${ }^{22}$ para discernir el funcionamiento de algunas tramas de dicha cultura.

7 Metodológicamente, seleccioné un caso cuyo análisis ayudará a comprender una forma de agenciamiento de esta cultura jurisdiccional por una mujer esclavizada. El propósito es visualizar de qué modo, aún en condiciones de precariedad jurídica, podían activarse los engranajes de la cultura jurisdiccional en el Río de la Plata.

\section{Presentación del caso}

8 Teodora Álvarez quebrantó las leyes y otras normas que hacían de ella una mulata esclava. Escapó del "poder de su ama” Antonia Zevallos y se marchó de Río Segundo, un poblado rural cercano a la ciudad de Córdoba en la Gobernación del Tucumán. Aun habiendo decidido su fuga y persistido un tiempo en ella, lo que agravaba su delito, el 15 de abril de 1758 acudió a la justicia ${ }^{23}$. Tenía 22 años, no sabía escribir y, por interpósita escritura de su patrocinante y los jueces que intervinieron en su causa, conocemos de sus padecimientos, similares a los narrados por otras mujeres esclavizadas en circunstancias análogas. Hacía un tiempo que había huido por el 
maltrato al que era sometida en aquella casa y en la presentación judicial pedía cambiar de amo.

9 Cuando invocó este derecho que la asistía ya no estaba en el lugar de residencia de la familia esclavista, ni siquiera en Córdoba, sede de la Gobernación del Tucumán, sino en otra jurisdicción: a más de 65 leguas de distancia ${ }^{24}$, en Santa Fe de la Vera Cruz. En esta ciudad del litoral paranaense de la Gobernación de Buenos Aires se hallaba conviviendo -no sabemos desde cuándo- con su marido. Al conocer que habían llegado a buscarla desde Río Segundo, Teodora se sintió "perseguida" y decidió acudir al auxilio de la justicia.

10 En su declaración expuso que el maltrato propinado por su ama y la madre de su ama, tenía origen en los celos que sentían por ella. Las mujeres con las que había convivido le recriminaban el ser objeto de satisfacción sexual de Thomas Zevallos, el padre de su ama y legítima propietaria. Paradójicamente, el celado, era su victimario y, sin ser su amo, había llegado a buscarla a Santa Fe.

11 Es posible que la joven se haya explayado en una descripción más detallada de los motivos de su fuga que no tenemos posibilidad de conocer, ya que el juez, si bien agregó los ítems de rigor para que se autorizase el cambio de amo solicitado por Teodora -falta de vestido y alimento- cerró la presentación apuntando, vagamente, que también había "otras razones que tubo para ello, y no son dezentes ponerlas por ahora por escripto" 25 .

12 Como es frecuente en este tipo de causas, ya sea por desistimiento de la querella, acuerdo entre las partes, pérdida de la sentencia o porque algunos fragmentos del expediente se suelen traspapelar en los archivos, no conocemos la resolución final y, a diferencia de otros casos, tampoco sabemos cómo siguió la vida de esta mujer después del juicio. Bastaron unos escribanos, unas hojas y algo de tinta para que su breve paso por la justicia le reservara una identidad socio-jurídica, racial y delictiva perdurable. Así, desde un expediente compuesto con intervenciones que se sucedieron en 100 días (entre el 15 de abril y 19 de julio de 1758) llega hasta el presente: "Teodora esclava mulata fugitiva".

13 Su historia puede enlazar con la de otras "esclavas", "negras", "mulatas" o "morenas" fugitivas buscadas por la justicia en el Río de la Plata y conectar con las problemáticas de algunos estudios sobre cimarronaje que plantearon interrogantes acerca de la voluntad o autonomía de las mujeres negras frente a la huida. Hay quienes hipotetizaron que las mujeres habrían estado menos interesadas que los hombres a la hora de abandonar la casa esclavista, y refrendaron esta hipótesis con la lectura de un dato sobre la población adulta de mujeres en las comunidades cimarronas que asignaba un alto porcentaje a mujeres raptadas "para satisfacer las necesidades biológicas y sociales de los hombres cimarrones" 26 . Algunos estudios, ponen en evidencia otros casos en los que ni el embarazo, ni los hijos, ni el cambio de amo, parecen haber sido factores disuasivos a la hora de huir ${ }^{27}$. Por otra parte, como lo han mostrado otras investigaciones, la fuga no solamente tenía como fin último alcanzar la libertad. A veces, las mujeres parecieron estar dispuestas a arriesgarlo todo para escapar de la brutalidad de sus amas y amos, de situaciones en extremo abusivas y tiránicas, como lo expone en alguna medida la causa de Teodora, temporalmente cimarrona -aunque no en una comunidad cimarrona ${ }^{28}$ - y presionada por la fuerza de los hechos a recurrir a la justicia. 
En un estudio sobre la esclavitud quiteña, Manuel Lucena Salmoral, uno de los historiadores más prolíficos sobre la esclavitud en Iberoamérica, manifestaba con cierta sorpresa que en Indias "donde todo se legisló" existía una "orfandad legislativa" respecto de "los esclavos". Esta "orfandad legislativa" -afirmaba- fue contemplada en las políticas de reformas borbónicas y pretendió rectificarse durante el reinado de Carlos III, cobrando cuerpo una producción jurídica específica, conocida como Código Negro o Códigos Carolinos ${ }^{33}$. El investigador no formuló esta sentencia por desconocimiento de la documentación relativa a la regulación de la esclavitud previa a estos "códigos", sino condicionado por una perspectiva teórica que omite las consideraciones expuestas en la introducción de este artículo sobre la noción de ley y las vinculaciones de la Corona, la corte y los jueces con las leyes en el siglo XVIII. A medida que se avanza en la lectura de su libro y se recorre su vasta producción, se puede colegir la pluralidad normativa sobre la esclavitud vigente en esta centuria, que incluso él mismo se dedicó a transcribir ${ }^{34}$. Un rasgo diferencial de los Códigos Carolinos puede haber sido el ser emergentes de la supresión de los intermediarios en la trata negrera, que abrió los puertos a la introducción masiva de africanas y africanos esclavizados, urgiendo regular de manera más sistemática esa presencia e integración en los territorios coloniales ${ }^{35}$. No obstante, como también es corriente en la historiografía específica sobre el tema, se ha tratado sobre la resistencia a dichos códigos y se ha sostenido que los mismos nunca llegaron a aplicarse. Desde la 
perspectiva de este artículo, corregiremos esta suerte de plataforma de presupuestos jurídicos sobre la esclavitud señalando que, antes de este particular cuerpo jurídico carolino -que por otra parte fue objeto del mismo tipo de concepción, elaboración y uso que otras leyes de Antiguo Régimen ${ }^{36}$ - una gran cantidad de normas y disposiciones trataban de las personas esclavizadas. En orden general, este segmento de la población seguía amparado por las leyes de las Partidas a las que, sin invalidar, restañaban otras particulares: reales cédulas y pragmáticas, provisiones del Consejo de Indias y todas las otras disposiciones que se dictaban en las diócesis, gobernaciones o virreinatos o por las normas que dimanaban de las jurisdicciones locales a través de las actas capitulares, las ordenanzas o los procesos judiciales.

19 No nos ocupa en este trabajo recomponer de entrada esa ingente producción jurídica sobre la esclavitud que el lector o la lectora podrá consultar en otros trabajos ${ }^{37}$. Por el contrario, procediendo de modo similar a como lo hicieron las y los coetáneos, nos introduciremos y nos serviremos de ella al hilo de los procesos judiciales, en la medida en que lo reclame el análisis de las circunstancias que rodearon o que podamos relacionar con los hechos que afectaron a Teodora Álvarez.

\subsection{Por qué acudir a la justicia}

Como se expuso en el relato del caso, Teodora Álvarez había llegado a Santa Fe con algo más de 20 años y su arribo no quedó registrado por haber sido una visitante ilustre, ni por ser parte de un contingente esperado para incrementar activos demográficos, sino porque acudió a la justicia ${ }^{38}$. Había salido "fugitiva" desde Río Segundo, luego de haber recorrido un largo trayecto -no sabemos si a pie, sola o en compañía- y se acomodó un tiempo en la ciudad donde convivió con su marido hasta que llegó a buscarla Thomas Zevallos. En aquellas circunstancias, con la amenazante presencia de su victimario en la ciudad, si bien Teodora depuso su actitud cimarrona, no cedió en su decisión de no regresar a aquella casa. La protección judicial se erigía como vía alternativa para resistir, si no el retorno a la esclavitud, al menos, a la situación de maltrato que había padecido.

21 Con sus modulaciones jurídicas, el maltrato fue una de las faltas por las que se podía castigar a amas y amos. Las denuncias que reiteradamente llegaron a la Corte por este móvil habían surtido efecto normativo, como el que documenta, entre otras, la real cédula del 12 de octubre de 1683 enviada a todas las audiencias y gobernadores indianos para castigar la sevicia. Según reza esta cédula, sevicia o maltrato suponía no asistir a las esclavas y esclavos con la doctrina cristiana, vestido y educación.

“...y aunque por derecho está prevenido el remedio conveniente para la enmienda destos daños, de forma que siempre se averiguase exceso de sevicia en los amos, se les obligue a venderlos y demás amas se les castigue, si el caso lo pidiese" ${ }^{39}$.

Se ha interpretado que esta obligación de venta cuando se demostraba sevicia operó como una "opción legal" que la corona "otorgó a los esclavos", quienes paulatinamente lo fueron convirtiendo en "un instrumento muy poderoso contra sus amos". La opción, según interpreta Tovar, fue utilizada como "un derecho" y como "un recurso contestatario" 40 . Sin embargo, la tramitación de una causa por sevicia no era sencilla. En principio porque nadie que acusara a su amo o a su ama contemplaría remotamente la posibilidad de seguir viviendo bajo el mismo techo. Una forma de iniciarla sería escapándose de la casa donde trabajaba y recurriendo a un juez. Luego seguirían las 
averiguaciones, la elección de testigos y, mientras se substanciaba la causa, se le brindaría amparo en un sitio apropiado de acuerdo fuera varón o mujer. Las mujeres podrían ser depositadas en una casa de recogidas o en la casa que se designara como refugio o, incluso como sucedió en Santa Fe, la cárcel pública podría tener destinada una celda especial para mujeres. Hasta que se sustanciara el pleito, correspondía que amo o ama pagase a la Real Hacienda 1 real diario por la manutención del "esclavo" en depósito. Esto último, que no siempre consta en los casos de los varones, no se registra ni una vez en el caso de las mujeres, al menos en lo que va de la investigación.

Ahora bien, Teodora ni eligió la vía judicial como primera opción, ni había una sola puerta de entrada a la justicia ni un único juzgado al que podía recurrir para hacer valer este "derecho" de demandar a su ama por sevicia y pedir carta de venta para el cambio de propietaria.

\section{3 ¿Huir o pedir justicia?}

24 La presentación de las mujeres esclavizadas ante la justicia, generalmente, se ha contextualizado en ámbitos urbanos donde, casi siempre, realizaban las tareas pertinentes a su condición servil, las que suelen vincularse con labores domésticas, aunque nos consta que realizaran otros trabajos que implicaban franquear las puertas de la casa de sus amas y amos. Al habitar la trama urbana, ya sea de ciudades importantes como sede de gobernación o de pequeñas ciudades, se ha indicado que tenían mayores posibilidades de acudir a algún foro para hacer sus reclamos ${ }^{41}$. Sin embargo, como vimos, no podemos fijar a Teodora en esas condiciones en el momento de presentarse a la justicia.

Río Segundo, su lugar de procedencia, fue uno de los curatos más poblados de la jurisdicción de Córdoba, beneficiado relativamente por sus actividades productivas y por el Camino Real que lo surcaba, comunicando a Buenos Aires y Santa Fe con el Alto Perú. Era una zona de paso obligado en el comercio virreinal y sitio elegido para postas antes de cruzar el río que le daba su nombre. A pesar de su dinámica población, era un poblado rural probablemente disperso, donde las autoridades judiciales más próximas seguramente fueran los jueces pedáneos ${ }^{42}$.

Como fuera que haya sido, lo cierto es que Teodora no debe haber percibido las condiciones adecuadas para plantear sus reclamos por la vía judicial en su lugar de residencia, ni siquiera la posibilidad de hacerlo en la más cercana ciudad de Córdoba.

Aunque objetivamente comprensible, su decisión de huir es significativa a la luz de otras experiencias judiciales de personas esclavizadas que pasaron por castigos muy severos, incluso en la misma jurisdicción de Córdoba ${ }^{43}$. No es improbable que en Río Segundo circularan voces sobre la rigidez de las sentencias de los jueces cordobeses, la dureza de los castigos que, como bien observó Alejandro Agüero, siendo pocos los más extremos, fueron ejemplares ${ }^{44}$.

Tampoco es improbable que Teodora haya tenido noticias sobre las consecuencias de la fuga. La fuga siempre fue castigada con azotes. La cantidad de azotes que amas y amos podían aplicar varió, no tanto con el tiempo, sino de acuerdo con la fuente normativa que se invocara, la costumbre, inclusive. Pero tampoco era necesaria ninguna inspiración jurídica y siempre era un momento oportuno para innovar si se trataba de aplicar penas correccionales que marcaban para siempre los cuerpos y subjetividades de criadas y $\operatorname{criados}^{45}$. Por atentar directamente contra los intereses de amos y amas, 
este tipo de delito fue el menos tolerado. Si bien se ha dicho que hubo una atenuación de 100 a 25 azotes en algunas faltas a partir de $1783^{46}$, no ocurrió lo mismo para la fuga sobre la que aún en 1790 podía inspirar una Real Cédula como la que establecía que "el esclavo que se fugase recibiría 100 azotes y 6 meses de cadena" ${ }^{47}$.

Si consideramos que la fuga, además de ser uno de los delitos más fuertemente castigados corporalmente, quedaba consignada notarialmente, la decisión de una mujer esclavizada de huir es doblemente significativa. La fuga no solo pasaba a formar parte de una suerte de prontuario desacreditante e influyente en el mercado al tiempo de tasar "esclavas" y "esclavos", como advirtió Saguier, sino también estigmatizante al tiempo de recomponer vínculos y relaciones ${ }^{48}$.

En conocimiento, o desconociendo lo que podía ocurrirle, Teodora huyó y no hay muchas variantes que imaginar sobre por qué, de todos modos, lo hizo.

\subsection{Pedir justicia ¿Cuándo? ¿Dónde? ¿A quién?}

En su huida, dejó atrás la jurisdicción de la Gobernación del Tucumán en la que estaba comprendido el curato de Río Segundo y se asentó en Santa Fe, en la Gobernación de Buenos Aires. Ambas gobernaciones conformaban el espacio jurisdiccional rioplatense antes de que el topónimo Río de la Plata nombrara al último virreinato hispánico, creado en 1776.

Hasta esa fecha, sendas gobernaciones coincidían aproximadamente con los territorios diocesanos nombrados del mismo modo y estaban dentro del ámbito jurisdiccional de la Audiencia de Charcas, bajo el mando del virrey del Perú. Aunque lejos de la sede limeña, del superior tribunal de justicia real y de la audiencia arzobispal, ubicados en La Plata, provincia de los Charcas (hoy Sucre, Bolivia), este territorio no estaba vaco de oficios de justicias.

33 El espacio jurisdiccional rioplatense, imbricado en el más vasto de la Monarquía Hispánica, se caracterizaba por contar con una multiplicidad de agentes con potestades judiciales. Ya sea que estas potestades judiciales dependieran de las jurisdicciones seculares o eclesiásticas, todas derivaban de una sede de atribución de iurisdictio: el rey o, en su defecto, y en ocasiones sin su beneplácito, la reina ${ }^{49}$.

Así se conformaba el complejo campo de la justicia. Más abigarrado en sedes de gobernación y obispado como eran Córdoba y Buenos Aires donde los gobernadores eran justicia mayor y vicepatronos de los obispos. Y algo menos en Santa Fe, pero donde, incluso en zonas rurales y de fronteras, se podía ocurrir a distintos jueces ${ }^{50}$.

En el lugar en el que se encontraba Teodora, las primeras instancias de la justicia santafesina eran cubiertas por alcaldes ordinarios de primer y segundo voto y jueces vicarios eclesiásticos ${ }^{51}$. Junto con estos jueces, y en calidad de justicia mayor, el teniente de gobernador era el referente de la jurisdicción real en el territorio municipal y quien conocía las causas en grado de apelación.

El caso de Teodora, sin ser excepcional, nos recuerda una experiencia de la condición colonial de este entramado jurisdiccional hispánico-católico patriarcal. Mujeres y varones indios, negros y mestizos tenían la vía judicial emergente de la alteridad jurídica planificada para súbditos y vasallos de la monarquía: los oficios, igualmente judiciales, del protector de naturales y el defensor de pobres y menores ${ }^{52}$. A este último recurrió Teodora. 

de amo. para tal presentación? dicha mulata"58.

Como ha sido señalado por Carolina González Undurraga respecto de los procuradores o abogados de pobres del Tribunal real de Santiago de Chile ${ }^{53}$, los defensores de menores y pobres de Santa Fe tampoco estuvieron dispuestos a acceder al amparo judicial cada vez que acudían a ellos. De allí que deba subrayarse la intencionalidad de Francisco Martínez de Rozas, un vecino que se había desempeñado como alcalde de segundo voto y juez de menores, alférez real en depósito y procurador general, y que ahora lo hacía como defensor de menores y pobres ${ }^{54}$.

El 15 de abril de 1758, él redactó un brevísimo pero preciso historial de vejaciones con el que cargaba su patrocinada, tantas veces vapuleada con apenas 22 años. Al comunicar una imagen de su cuerpo escuálido y apaleado, con un vestido desteñido y rasgado, "viéndose toda hecha pedazos", el Defensor, subrepticiamente, cargaba tintas sobre la sevicia padecida y atenuaba las cargas del delito de fuga que pesaba sobre Teodora, procurando vehiculizar otro derecho que la resguardara como era el cambio

\subsection{El patrocinio y los vicios del procedimiento}

¿Ante quién la patrocinó el defensor de menores? ¿Había una actuación judicial previa

El defensor de menores y pobres de Santa Fe asumió su representación ante el juez de menores, a la sazón, el alcalde ordinario de segundo voto Pedro Mihura. Aunque no consta expresamente, hay indicios de intercambios verbales previos. Todo parece indicar que Thomas Zevallos, llegado desde Río Segundo, había ocurrido ante el juez de menores reclamando a Teodora para regresarla a la casa. De allí que el Defensor estableciera que no estaba procediendo según derecho porque el citado Zevallos se había presentado "con poder extrajudizial â llevar a la dicha Mulata"55.

En clave de cultura jurisdiccional, el Defensor declaraba el derecho para Teodora comunicando al juez de menores que su defendida tenía "justos motivos para no poder ir" con él ${ }^{56}$. Es decir, dejó en segundo plano el delito de fuga, se negó a entregarla a Zevallos y suplicó al juez que le tomase declaración a Teodora. Como "esclava" la asistía el derecho de solicitar otro amo y en eso se afirmaba el Defensor al comunicar que en la ciudad había quien podía comprarla y dar "remedio, de que debe y pretende valerse para evitar ofensas a Dios nuestro Señor el solicitar otro amo"57.

El juez de menores de Santa Fe aceptó la solicitud de interrogarla. Ella compareció y se deduce que el Juez accedió al cambio de amo solicitado. Sin embargo, no convocó a una tasación en Santa Fe. Respetuoso del orden territorial ceñido a las jurisdicciones provinciales, envió una "carta informativa" a su par de la gobernación del Tucumán, el Juez y defensor de menores de Córdoba, para que se "perfeccione la venta que pretende

3 No respondió este juez, o al menos no consta su recepción, sino el general Joseph Galarza, familiar del Santo Oficio y justicia mayor de Córdoba.

Quienes oficiaban de justicia mayor en Córdoba, de acuerdo con Agüero, eran el gobernador residente, sus tenientes o tenientes generales; estos últimos eran designados para sustituirles en todo el territorio provincial durante su ausencia o para asistir de forma permanente en las ciudades del distrito. Galarza era teniente general y 
como justicia mayor podía conocer causas en grado de apelación, un recurso muy apreciado y frecuentado por quienes vivían en ciudades alejadas de las Audiencias ${ }^{59}$.

¿Pero en este caso, el justicia mayor actuaba en instancia de apelación? ¿Lo hacía de oficio o de parte?

En ejercicio de su jurisdicción el justicia mayor de Córdoba había llamado a la justicia ordinaria de Santa Fe a respetar un procedimiento judicial que veía viciado y compelió al alcalde santafesino a guardar la debida "urbanidad y buena correspondencia que en los tribunales de justicia debe haver" ${ }^{60}$. Si bien las potestades jurisdiccionales de sendas justicias eran delegadas por el Rey, el justicia mayor cordobés buscaba ejercerla en su territorio, de allí que ordenase arrestar a Teodora y a su marido para que fueran restituidos a Córdoba.

Es posible buscar alguna otra razón de su interposición entre los jueces menores de ambas ciudades. Detrás del pendón de familiar del Santo Oficio pueden esconderse atribuciones y prácticas que pueden orientarnos sobre su actuación. Como familiar, Galarza era un auxiliar laico de la Inquisición. Marcela Aspell ha consignado que los familiares eran una figura clave en la organización de los Tribunales inquisitoriales:

"A la deseada y temida salvación de las almas, la extrema consideración social, la reserva de sitios privilegiados en actos oficiales se le sumaba el intento de disfrutar de la jurisdicción inquisitorial, los familiares pretendieron la eximición de la jurisdicción ordinaria criminal y también de la eclesiástica, circunstancia que originó múltiples conflictos" ${ }^{\prime 1}$.

Aunque Galarza no antepusiera esta jurisdicción en su proceder judicial, sabemos por la misma autora que, en Córdoba, los familiares solían actuar de consuno con la justicia ordinaria en los arrestos y traslados de los reos. Tal vez Galarza conocía al juez de menores de su ciudad y fue suficiente tomar conocimiento informal de la causa para intervenir sin más en un hecho de importancia como era la restitución de "una esclava".

Esta es una pista que viene a completarse con lo que explica Agüero sobre los mecanismos de la justicia penal en el mismo ámbito cordobés, donde los jueces inferiores tenían la obligación de consultar las sentencias con los superiores antes de ejecutarlas. Aunque se tratase de un mecanismo de control procesal, especialmente desarrollado para las causas criminales graves, no es improbable que se haya puesto a funcionar activado por un posible vínculo entre Galarza y Zeballos o por los propios intereses del justicia mayor en realizar la subasta de "una esclava" en un mercado que, si no controlaba, al menos por cercano, conocería lo suficiente como para beneficiarse directa o indirectamente, beneficiando a algún conocido interesado en la compra.

Pero con todas a su favor, no le resultó fácil al justicia mayor cumplir su cometido. $\mathrm{Ni}$ siquiera sabremos aquí si lo cumplió, porque el juez de menores de Santa Fe jugó una última carta en el juego de las jurisdicciones: en lugar de responder al exhorto del juez cordobés, enviando a Teodora y al expediente, decidió fijar la causa en territorio santafesino.

\subsection{La justicia eclesiástica}

51 El juez de menores de Santa Fe sentó el caso en la jurisdicción eclesiástica. Es en el archivo del juzgado eclesiástico donde hallamos el pleito que debió resolver el vicario 
Juan Ignacio Lacoizqueta, aunque en esta oportunidad nada sepamos de su proceder, excepto que aceptó el expediente.

¿Cómo lo hizo? Prácticamente, adjuntando la orden de Galarza a la presentación de Teodora, notificándola a ella, a su marido, a Thomas Zevallos y a Antonia del traslado de la causa mediante escribano público y remitiendo el expediente al juez eclesiástico.

Jurídicamente, había varios atajos para fundamentar que el expediente que contenía el pedido de cambio de amo de Teodora llegase al juzgado eclesiástico de Santa Fe. Tres razones jurídicas principales conviene tener presente. En principio, porque la justicia eclesiástica no se reducía al fuero de la consciencia, al fuero interno examinado en la confesión; en segundo lugar, por la existencia de materias de fuero mixto y, finalmente, porque la justicia eclesiástica se erigió como foro de las personae misserabiles.

En la relación con la primera consideración, el fuero eclesiástico no fue sólo el lugar designado para la discusión de las causas en asuntos espirituales o eclesiásticos, sino que también devino fuero por excelencia de las causas en que estaba implicada la reparación de un daño o el cumplimiento de una promesa, un ensamblaje entre la esfera de la ética y el derecho ${ }^{62}$. Esto es algo que conviene complementar con el sentido inverso señalado por Carlos Garriga: tampoco la justicia civil era solamente una justicia de fuero externo, de allí que el autor haya destacado a esa dualidad "fuero externofuero interno" como uno de los aspectos configuracionales del derecho antiguorregimental en ese complejo normativo más vasto en el que entraba en liza con la teología moral ${ }^{63}$. Puede apreciarse, entonces, la diferencia entre el factor sacramental de la administración del perdón, la administración legal de las penas canónicas ${ }^{64}$ y las resoluciones derivadas de sentencias o mediaciones -más o menos formalizadas- de los jueces eclesiásticos, también denominada "justicia penal eclesiástica"65.

Una segunda condición que explica la competencia de los jueces eclesiásticos para mover causas que excedían a la propia justicia del fuero eclesiástico, como las que derivó el alcalde, juez de menores, es el mixti fori. Esto es, la existencia de materias en las que tenían competencia tanto los jueces seglares como los eclesiásticos ${ }^{66}$. En otros trabajos hice referencia a estas causas en las que el conocimiento del juez eclesiástico no excluyó el de los jueces seculares ${ }^{67}$. En este sentido, el expediente escogido para el presente análisis es representativo de aquellas otras causas en las que el conocimiento de los jueces seculares no excluyó el del juez eclesiástico, con lo cual el caso viene a complementar ese cuadro de convergencias entre las distintas varas de la justicia que animaba la cultura jurisdiccional.

$56 \mathrm{Y}$, en tercer lugar, también podemos encontrar una explicación a esas comparecencias o peticiones ante el vicario foráneo, en tanto que la justicia eclesiástica, como anticipamos, se erigió como foro de las personae misserabiles. Ante los vestigios de las vidas de algunas de las mujeres y las prácticas esclavistas del clero, la inclinación a la misericordia puede resultar una falacia, de allí que convenga, una vez más, recuperar la semántica de este término que definía ese rol judicial de los ordinarios -los obispos- los provisores o los vicarios, con personas que no gozaban del privilegio del fuero eclesiástico.

57 Así como en el estatuto de minoría la condición de menor no refería a la edad, la condición de miserable no refería a un estado de miseria económica, sino moral. Como ha explicado Thomas Duve, "persona miserable" remite a una categoría jurídica aplicada a personas que eran consideradas incapaces de valerse por sí mismas. 
Integrada en el Corpus iuris civilis y acogida en el ius commune, tanto en su vertiente civil como, sobre todo, canónica, esta categoría ancló en Hispanoamérica dilatando su carga semántica y las derivaciones de su uso ${ }^{68}$. En el tiempo que estamos analizando ese uso se vulgarizó $^{69} \mathrm{y}$ en las comparecencias -tanto las presentaciones patrocinadas por defensores o protectores, como las realizadas de puño y letra de las mujeres- es un concepto asumido por ellas. Pobres, viudas, huérfanas o esclavas; españolas, criollas, indias, negras o mestizas, comparecían diciendo "ser" miserables, para invocar la tutela de los defensores y la protección judicial.

Se puede corroborar que razones jurídicas no faltaban. Pero esta vez, ¿era correcto el procedimiento? ¿Hizo bien el juez de menores en derivar la causa a la jurisdicción eclesiástica? ¿Por qué no la derivó a la justicia eclesiástica de Córdoba?

Recordemos que, desde que se había iniciado el trámite judicial, en dos oportunidades, dos oficiales de justicia de distintas jurisdicciones habían alegado distintos "vicios" en el procedimiento. No obstante, lo que aquí cuenta es lo que actuaron los protagonistas y en este sentido no constan objeciones.

De acuerdo con el alcalde, le competía al juez eclesiástico determinar "lo más arreglado a derecho", en principio, porque Teodora se había casado con Vicente Calderón, reconocido en su indefinido mestizaje con lo negro, pero libre. Por lo tanto, no estaba sujeto a la casa de Thomas Zevallos. Obligar a los cónyuges a marchar a Córdoba hubiera representado forzar a Vicente. Regresarla a ella sola supondría impedir el precepto de la vida maridable. Razón por la cual era la materia "mas qe [sic] eclesiástica o matrimonial" y le correspondía a esa jurisdicción ${ }^{70}$. Pero, además, el juez alegó que era lo más acomodado a derecho por las "excepciones que por causa fundamental tiene expuesta por su declaración Theodora parda esclava para no poder ser arresstada con su marido Vicente Calderón"71.

61 Fulguran así, en estos procedimientos, las manifestaciones del carácter configuracional de este espacio jurisdiccional. En lugar de responder al justicia mayor de Córdoba que protestaba el mal procedimiento de las justicias santafesinas, el juez de menores de Santa Fe le encontraba la vuelta jurídica-judicial para derivar la causa a la jurisdicción eclesiástica. Invocando esta "causa fundamental", hizo caso omiso al juez cordobés que sostenía que la "mulata fugitiva" había declarado "sin las precisas circunstancias que para semejantes actos previene el derecho" 72 . El alcalde y juez de menores de Santa Fe también desconoció el respaldo jurídico en el que se apoyaba el justicia mayor de Córdoba para insistir en que siendo Teodora de "los menores sujetos a Thomas Zevallos, vecino de Río Segundo" la causa estaba bajo su jurisdicción.

Recordemos que dentro de esos "menores sujetos a" Zevallos estaban comprendidas las dos mujeres: una por ser su hija y viuda; la otra, además, por ser "esclava mulata".

\section{7. "Esclava, mulata, fugitiva": categorías jurídicas, relacionales y subjetividades}

63 Mujer como su ama y mestiza como su marido ¿La minoridad de género y racial eran condiciones que Teodora compartiera en igual grado que sus convivientes más próximos? 

los vínculos de esclavitud de acuerdo con las leyes que permitían al marido comprar la libertad que él ya tenía. Vicente, aunque varón libre, era un joven a cuyo nombre se le adosaban etiquetas raciales como las que acorralaban a Teodora: en los registros aparecían nombrados, alternativa y dubitativamente, como mulatos o pardos. Como puede verse, el interés por identificar a las personas en la gradación pigmentocrática afín a su condición de subalternidad, no se resolvía con una sola ni con una definitiva etiqueta racial. Así se tratase de una misma persona, ésta podía variar de acuerdo al notario o interesado que tuviera mayor ascendiente en el trámite que generara el documento. Aunque inestables y ambiguas, estas etiquetas eran imprescindibles a la hora de impartir justicia, ya que constituía una seña para que los jueces, comprometidos a "guardar la equidad", lo hicieran según el principio antiguo regimental de la justicia distributiva; esto es, a dar a cada quien lo que le correspondía según su estatus o calidad.

69 En esta cultura jurisidiccional, la condición de género que diferenciaba a Teodora de otros varones esclavizados y de su marido mestizo libre, la acercaban en algún punto a su ama. Ésta última, como viuda, podría haber hecho uso de una ventaja jurídica como era la de escapar a la tutela masculina, pero, como ya se expuso, esto no ocurrió y eso también afectó a su esclava. No fue la propia Antonia, ni un patrocinante, sino 
precisamente su padre quien, enterado del paradero, partió a buscarla a Santa Fe. Allí, sus pretensiones chocaron contra la objeción jurídica del defensor de Teodora que también resguardó a su ama como "menor".

70 El Defensor no actuaba por bondad, ni por fuera del patriarcado colonial. El paternalismo jurídico y judicial protegía el patrimonio de Antonia. Aunque española y propietaria esclavista, era mujer, como mujer era viuda y como viuda podía ampararse en la categoría de persona menor, miserable. A esto se refería el Defensor al argumentar que Teodora "era bien de Menores". No entregarla al padre de Antonia, no implicaba la liberación de la joven, sino restituir el valor de un bien recibido en herencia. Al hacerlo declaraba el derecho y consolidaba las gradaciones socioestamentales igualmente generizadas. Teodora, siendo menor y miserable lo era un poco más por serlo de su ama, otra menor y miserable.

71 En esta cultura jurisdiccional, la minorización de género podía restañarse con la estamental, a fuerza de normas y también de azotes. Otros flejes subalternizantes como la sexualidad y la raza se activaban en escenarios de la iuris dictio. Siendo mujeres y menores, su sexualidad estaba bajo control patriarcal. Ambas podían pecar de "liviandad", lo que en aquella cultura jurídica configuraba un delito perseguido por varones y castigado con azotes. Pero en mujeres como Teodora (mulatas pardas "oscuras") sólo había la posibilidad de sufrirlos y en mujeres como su ama, además, podrían aplicarlos, a condición de que contasen con la venia de un juez.

72 Pocos años antes de los sucesos que aquí se analizan, en 1755, había corrido un auto del Gobernador del Tucumán quien:

"Ynformado que en toda la Provincia y prinsipalmente en esta ciudad tienen por costumbre los Alcaldes ordinarios azotar con yndesencia, en el Rollo a las Mulatas y aun a mugeres blancas con el pretexto de ser correspondiente castigo a sus delitos de libiandad, cuyo abuso debe extinguirse enteramente por no acostumbrarse en otros Reynos y Provinzias y por lo inhonesto que es a la vista y de mal ejemplo: ordeno y mando que para azotar Negras, Zambas o Mulatas Pardas oscuras por semejante delito, lo manden a executar los Alcaldes ordinarios en secreto y por mano de mujeres, del medio cuerpo para arriva, que siendo Mestizas, Mulatas Quarteronas o chinas ni solteras ni casadas, por modo alguno se usara con ellas tal castigo por delito de flaqueza, sino que se procuraran desterrar inmediatamente, o depositar en casas timoratas o desentes, pero si el delito fuere mayor que pida preciso castigo publico para su escarmiento esemplar a las demas, se podra hazer en el Rollo asimismo en las espaldas, dandole el número solamente que baste a contener los exzesos y que sirva de castigo sin parecer por lo cruel o sangriento, Martirio [...] Y en el delito de flaqueza de naturaleza, no pasen del numero de doze azotes, prozediendo dichos Alcaldes en esta Ordenanza con toda reflexión"75.

73 La intervención no solo es expresiva de muchos de los conceptos que ha sostenido esta propuesta analítica (la noción de ley y Derecho, sus vínculos con la justicia, los mecanismos de producción jurídica), sino un contundente documento del ambiente en el que Teodora tomó sus decisiones. Es también el ambiente que infundiría las ideas sobre su sexualidad, el que habilitaba el acceso ilimitado al cuerpo de las mujeres negras y mulatas, donde se justificaría el comportamiento sexual de Thomas Zevallos y donde su mujer y su hija podrían cultivar sentimientos tan paradojales como los celos por las agresiones sexuales que padecían sus esclavas.

La extensión de la cita se justifica, también, por ser otra cara del prisma donde observar ese proceso mediante el cual, legislando y "reflexionando" con azote en mano -como mandaba el Gobernador- se operaba una suerte de generización y racialización de la 
sexualidad $^{76}$. En estas condiciones de género y sexualidades racialmente diferenciadas, podemos recuperar parcialmente la observación de Mario Rufer sobre que la mujer era convocada para "la acción punitiva" pero no para la decisión de juzgar. Con base en estas ordenanzas, afirmó el autor, la mujer "es -como el verdugo- el instrumento infamante que castiga y purga a la vez, y a través del castigo ritualiza el ejemplo de lo que a ella misma podría sucederle" 77 .

Pero Teodora no tenía chances de entrar en ese ritual como verduga. En Teodora confluían además de la subalternidad de género, el estatuto jurídico de esclava, la "nota de la mala raza"78, las connotaciones bestiales de la sexualidad de las "castas"79 y el nuevo estigma delictivo que adquiría en el terreno judicial. En los autos judiciales Teodora fue identificada como "esclava mulata fugitiva" y esto pudo reproducirse en la documentación notarial tantas veces como haya entrado al mercado de compra, venta, alquiler y préstamos de esclavas y esclavos. Sólo por interés de las o los propietarios podría ocultarse la marca delictiva de la fuga, pero sin garantías de que no fuera a reaparecer en las redhibitorias ${ }^{80}$.

\subsection{La agonía del expediente}

Todo lo actuado por el alcalde y el defensor de menores santafesinos, aunque jurídicamente ajustado a las normas que invocara cada uno, resultaba -según el juez cordobés- en gravísimos inconvenientes para sus potestades judiciales ejercidas en nombre de la Real jurisdicción. En virtud de ello, había ordenado que le enviaran la mulata a "su amo" -nótese que a diferencia del defensor y el juez de menores santafesinos no reconocía a Antonia de Zevallos como legítima propietaria- y que, con el marido, se presentaran en su juzgado, "pues siendo (el amo) domiciliario en este distrito le compete derechamente a los juezes de ella su conocimiento hasta la última resolución"81. Desconocemos si el criterio territorial del juez cordobés se impuso al recurso jurídico de la jurisdicción eclesiástica que remitía a la salvaguarda del matrimonio y, si no a la violación -ya que este no era un delito tipificado de amos a esclavas- al delito de los amos de prostituir a sus esclavas ${ }^{82}$.

Tampoco se pudo saber -al menos en esta etapa de la investigación- qué camino tomó el proceso luego de que el juez eclesiástico recibió la orden del juez de Córdoba. No hay notificaciones de copia ni traslado del expediente. Quizás no hubo sentencia y, si la hubo, no hay un solo modo en que esto puede haberse resuelto.

Entramos en un camino presuntivo, pero con pistas que permiten reflexionar en los engranajes de la cultura jurisdiccional.

Si lo que prevaleció fue el criterio territorial fijado por la residencia de los propietarios esclavistas, el proceso puede haber seguido en Córdoba. En cambio, si primó la "razón fundamental" que afectaba a Teodora, la causa puede haber concluido en la jurisdicción de Santa Fe con la intervención del vicario eclesiástico, el concurso de la justicia ordinaria y la consecuente tasación, subasta y cambio de amo.

Como se afirma en la introducción, en las condiciones específicas de Antiguo Régimen el Derecho no era asimilado como Ley. Los jueces, llamados a establecer la equidad en cada caso, al tiempo que abonaban el predominio de la casuística, hacían más dúctil la apelación al derecho y, como he intentado mostrar hasta aquí, más elástica la trama de las jurisdicciones. 
81 Podríamos plantear, una vez más, el tema de los conflictos jurisdiccionales, consustanciales a estas sociedades. La perspectiva propuesta, sin embargo, permite trascender esta problemática y penetrar en una trama jurisdiccional activada por una mujer que toma la decisión de huir de la casa de su ama.

82 Así fuera por premeditación, con complicidad o impulso súbito, no podemos dejar de inferir la silenciosa gestación de una acción que contradijo de plano todo aquello que hacía de ella una "esclava" y puso en marcha los engranajes de la cultura jurisdiccional. En suma, se impuso restituir su subjetividad imaginando los instantes en los que, pese a la ruda vida que llevaba, pudo madurar la idea de la fuga sopesando "las abrumadoras ventajas de sus opresores", no sólo en el sentido "militar" que planteó A. O. Thompson, o en aquel otro que mediante la categoría de interseccionalidad de raza y género, han visibilizado los estudios decoloniales de género o la epistemología del feminismo negro, sino también todas las ventajas emergentes de esa cultura jurisdiccional que las mujeres esclavizadas parecen haber estado dispuestas a enfrentar y torcer a su favor.

83 Ella escapó y denunció las faltas de sus amos que estaban normativizadas. Parece haberlas conocido o, al menos, consiguió vincularse con quienes se las hicieron saber. En la documentación de base sólo aparecen nombrados varones: su marido, el Defensor de Menores, el juez eclesiástico y hasta el alcalde de segundo voto de Santa Fe parecen haber sido más sensibles a la causa de Teodora y, por tal razón, podrían haber suministrado los términos que, jurídicamente, mejor traducían sus padecimientos, así como los canales por donde encontrar un aliciente. No podemos descartar otras correas de transmisión en las que también participaran, voluntaria o involuntariamente, otros varones y otras mujeres.

84 Como ha sido señalado en otros trabajos, la falta de provisiones básicas como la ropa, los alimentos y la asistencia frente a la enfermedad, eran los motivos más invocados en estos reclamos ${ }^{83}$. No se trata de reclamos antojadizos, sino que refieren a la cultura jurídica ya asimilada o transmitida, compartida solidaria o interesadamente en el contexto judicial. Solidaridad e interés que podemos intuir hacia ambas partes del litigio.

85 Expuse la hipótesis sobre en qué medida y por intermedio de quiénes Teodora pudo haber conocido sobre la protección jurídica que la asistía a un cambio de amo frente a actos de crueldad y sevicia como los que denunció. Es posible que el Defensor cuando, en lugar de responder a la orden del juez de Córdoba, decidió derivarla al juez eclesiástico, no se sintiese movido por una justicia solidaria con Teodora, sino que estuviera interesado en que su venta se efectuase en Santa Fe. También el juez eclesiástico, defendiendo el deber de vida maridable asociado al sacramento del matrimonio o el abuso de prostitución, pudo haber defendido a Teodora para que continuara en Santa Fe con su marido. Y, asimismo, es posible que no la condenara restituyéndola a Córdoba, sino que accediera a su tasación y venta porque él mismo o algún conocido, tal como lo hemos planteado para el justicia mayor cordobés, se viera beneficiado con la operación.

De la parte de Thomas Zevallos, que resistía las normativas favorables a que Teodora cambie de amo, la cultura jurídica discurría entre intereses y solidaridades que también configuraban el derecho. La restitución no sería sin consecuencias para Teodora, en quien veía a una esclava que había cometido un grave delito como la fuga. 
87 Es sabido que, por el mismo delito, los castigos prescriptos a las personas esclavizadas eran más rigurosos que si eran cometidos por libres. Sin embargo, algunos análisis con base en expedientes judiciales han mostrado la interferencia de los amos en el proceso judicial para atenuar las penas de sus esclavos, a fin de no lesionar sus capacidades productivas, y la solidaria respuesta de los jueces en las sentencias y en las costas de los juicios $^{84}$. Pero no sucedía exactamente lo mismo con la huida de la casa esclavista que, como se dijo, era el delito menos tolerado. Si frente a otros delitos cometidos por el personal esclavizado, los esclavistas desconocían las penas y castigos prescriptos por las leyes reales y tendían a atenuarlos, cuando se trataba de una fuga, las desconocían para endurecerlas brutalmente. Si sumamos lo que se dijo más arriba acerca de la llamativa cantidad de expedientes sobre fuga y el clivaje de género, lo expuesto hasta aquí contribuye a una problemática que amerita seguir siendo investigada.

\section{Palabras finales: hacia una historia de la cultura jurisdiccional con la justicia eclesiástica, la raza y el género restituidos}

Desde esta asunción del campo de la justicia y de la cultura jurisdiccional a la que se restituyó la jurisdicción eclesiástica, no procedía separar en jurisdicciones aquel espacio que se presentaba como un complejo jurisdiccional de múltiples entradas y recorridos. El abordaje microanalítico del caso permitió mostrar que la decisión de acudir a la justicia a veces podía no ser la primera opción para resolver un problema y que bien podía postergarse como último recurso y no coincidir con el entorno judicial próximo. También se pudo observar que una de las manifestaciones de la precariedad jurídica de persona se hacía evidente en el momento que, al desertar de las obligaciones de la esclavitud, aunque no se tomara la decisión de hacerlo, se entraba forzosamente en el terreno judicial. En este terreno, incluso, la decisión de huir pudo ser interpretada como una expresión -ya no solamente de la cultura jurídica-judicial- sino también de algún tipo de saber o dominio del ambiente próximo jurisdiccional. Si los jueces actuaban desde sus culturas jurídicas, informadas por saberes legos y letrados, también es posible contemplar que a instancias del agenciamiento de las justiciables $\mathrm{y} / \mathrm{o}$ litigantes tornaran aquel crujiente y quebradizo hojaldre de jurisdicciones en una malla de potestades jurisdiccionales maleables.

Es sugerente, aunque no excepcional, que en esta cultura jurisdiccional distinguida por el paternalismo patriarcal y la colonialidad, esa potencial maleabilidad fuera activada por la decisión de una mujer a quien esa misma cultura le negaba la posibilidad de la condición jurídica de persona. El recurso categorial de interseccionalidad de raza y género en un análisis con perspectiva jurisdiccionalista se suma a los aportes críticos que se han ido ofreciendo, desde otras miradas, a las tradicionales tesis de la "benignidad" en la esclavitud y contribuye a pensar en un aspecto configuracional de la cultura jurisdiccional que otras investigaciones han soslayado.

El género, el sexo y la raza configuran una de las experiencias coloniales vividas por las mujeres esclavizadas, distinguiéndolas de los varones esclavizados y de otras mujeres, igualmente subalternizadas por el género, en cuyas experiencias operaban otras categorías interseccionales -religión, estatus, condición económica, estado conyugalque, asimismo, influyeron en la constitución diferencial de sus sexualidades, sus 
maternidades, sus economías domésticas, sus relaciones con las autoridades, entre otras.

91 De modo que este recurso categorial que ofrece la epistemología del feminismo negro fue útil para quitar el velo a algunas operaciones hermenéuticas trazadas desde engañosos universales. Sus planteos resultan especialmente estimulantes en cuanto que, si las categorías se entienden como homogéneas, operan selectivamente visualizando solo al dominante dentro de cada grupo. Así, "hombre" selecciona a los varones blancos, libres; "mujer" a las mujeres blancas libres; "negro" a los varones esclavizados, ingenuos o manumisos; negando la posibilidad de pensar aquello que, no solamente no se quiere mostrar, sino que se trata de invisibilizar y de silenciar, para hablar en su nombre. Este procedimiento que la intelectual india Gayatri Chakravorty Spivak, atribuyéndolo al discurso eurocentrista, definió como violencia epistémica, es "la manifestación de un proyecto de orquestación remota, de largo alcance y heterogéneo para constituir al sujeto colonial como Otro. Ese proyecto representa también la anulación asimétrica de la huella de ese Otro en su más precaria Subjetividad" $"$.

El análisis del paso de Teodora por la justicia, al tiempo que retomó su huella y abrió la posibilidad de su escucha en situación judicial, nos aproximó a un conocimiento más sensible de esa cultura jurisdiccional, donde ocurrían esas experiencias de las dominaciones concurrentes, donde se realizaba el cruce de las líneas que obraban en la subalternización sin conseguir ocluir completamente esos intersticios en los que podía operar también la agencia de unas mujeres que, en materia de cultura jurídico-judicial, sólo podemos distinguir por su mayor precariedad jurídica. Al utilizar la categoría de interseccionalidad de raza y género, en el terreno de la cultura jurisdiccional, fue inexcusable no reparar en el influjo de los recursos jurídicos y judiciales en la constitución relacional de las subjetividades. Ni las normativas más duras, ni las más contemplativas sobre la esclavitud de las mujeres, ni las más crueles disquisiciones sobre las penas correccionales y la administración del castigo, ni los mecanismos del "amparo" y la "protección" judicial, las desubjetivaban. Tampoco las protegían en el sentido ya cuestionado. Por el contrario, esos eran los dispositivos que las subjetivaban en el género y en la raza. Como asoma en este ejercicio analítico, mujeres como Teodora podían atreverse a quebrantar las leyes, aunque en las tramas de la cultura jurisdiccional fueran nulas o limitadas las posibilidades de mejorar sustancialmente su "estatuto" y su "calidad", determinados por la asignación racial, que sancionaba su precariedad jurídica. Aunque obtuvieran el cambio de amo, y aún la libertad, de todos modos, resultaban sexual y racialmente generizadas en esos engranajes de la cultura jurisdiccional. Vuelve entonces a interpelarnos el eco de la frase del epígrafe: "Quien se atrevería a quebrantar las leyes, si siempre temiesse que le podría suceder tal cosa?"

\section{Fuentes}

\section{Inéditas}

Archivo Histórico de la Arquidiócesis de Santa Fe de la Vera Cruz, AHASFVC, Querellas, Libro II, Santa Fe - Córdoba, Argentina, 15 de abril de 1758- 19 de junio de 1758, fojas $141-144 \mathrm{v}$. 
94 Archivo Histórico Provincial de Buenos Aires, AHPBA, 7-5-14-101. Real Audiencia, Disensos, Legajo 1, Santa Fe, 23 de junio de 1787- Buenos Aires, Argentina, 20 de febrero de 1804.

Archivo General de Indias, AGI, Indiferente General, Legajo 430, Libro 42, Real Cédula de Carlos II a las Audiencias y gobernadores de las Indias. Buen Retiro, 12 octubre 1683, fojas $297 \mathrm{v}-298 \mathrm{r}$.

\section{Publicadas}

\section{BIBLIOGRAFÍA}

Agüero, Alejandro, Castigar y perdonar cuando conviene a la República. La justicia penal en Córdoba del Tucumán, siglos XVII y XVIII, Centro de Estudios Políticos y Constitucionales, Madrid, 2008.

Agüero, Alejandro, "Las categorías básicas de la cultura jurisdiccional" en Lorente Sariñena, Marta (ed.), De la justicia de jueces a la justicia de leyes: Hacia la España de 1870, Consejo General del Poder Judicial, Madrid, 2007, p. 20-58.

Agüero, Alejandro, "Formas de continuidad del orden jurídico. Algunas reflexiones a partir de la justicia criminal de Córdoba (Argentina), primera mitad del siglo XIX", Nuevo Mundo, Mundos Nuevos, Debates, $\mathrm{n}^{\circ} 10,2010$, disponible en http://journals.openedition.org/nuevomundo/59352, consultado el 13 de octubre de 2017.

Agüero, Alejandro, "Ley penal y cultura jurisdiccional: a propósito de una Real Cédula sobre armas cortas y su aplicación en Córdoba del Tucumán, segunda mitad del siglo XVIII", Revista de historia del derecho, Buenos Aires, 2007, n³5, p. 13-45.

Albert Batista, Celsa, Mujer y esclavitud en Santo Domingo, CEDEE, Santo Domingo, 1993.

Albornoz, María Eugenia, Experiencias de conflicto. Subjetividades y sentimientos en Chile, siglos XVIII y XIX, Acto editores, Santiago de Chile, 2015.

Andrews, Reid, Los afroargentinos de Buenos Aires, Ediciones La Flor, Buenos Aires, 1989. 
Aspell, Marcela, “El Tribunal del Santo Oficio de la Inquisición en Córdoba del Tucumán”, ponencia presentada en el Congreso Internacional 'La Libertad Religiosa en el Siglo XXI. Religión, Estado y Sociedad, Facultad de Derecho y Ciencias Sociales, Universidad Nacional de Córdoba, Córdoba, 3-5 de septiembre de 2014. Disponible en www.calir.org.ar, consultado el 20 de noviembre de 2017.

Barriera, Darío G., "Voces legas, letras de justicia. Culturas jurídicas de los legos en los lenguajes judiciales. (Río de la Plata, siglos XVI-XIX)” en Mantecón, Tomás (ed.), Bajtin y la historia de la cultura popular: cuarenta años de debate, PubliCan, Universidad de Cantabria, Santander, 2008, p. 347-368.

Barriera, Darío G., "Justicias rurales: el oficio de alcalde de la hermandad entre el derecho, la historia y la historiografía (Santa Fe, gobernación del Río de la Plata, siglos XVII a XIX)”, Andes, Salta, 2013, n²4, p. 1-33.

Barriera, Darío G., "Del gobierno de los jueces a la desjudicialización del gobierno. Desenredos en la trenza de la cultura jurisdiccional en el Río de la Plata (Santa Fe, 1780-1860)" en Agüero, Alejandro \& Andréa Slemian (eds.), Jurisdicciones, Soberanías, Administraciones, Universidad Nacional de Córdoba, Córdoba (en prensa).

Barriera, Darío G. \& Forconi, María Celeste, "La compra de oficios como vía de acceso a las varas de justicia. Venalidad y coaliciones políticas en un cabildo rioplatense: la 'casa de los Monje' (Santa Fe, 1700-1750)", El Taller de la Historia, Cartagena de Indias, 2015, vol. 7, p. 255-305.

Bernand, Carmen, Negros esclavos y libres en las ciudades Hispanoamericanas, Fundación Histórica Tavera, Madrid, 2001.

Bentouhami-Molino, Hourya, Race, cultures, identités. Une approche féministe et postcoloniale, PUF, París, 2015.

Chakravorty Spivak, Gayatri, “¿Puede hablar el subalterno?”, Orbis Tertius, La Plata, 1998, vol. III, $\mathrm{n}^{\circ}$ 6, p. 175-235, disponible en: http://www.fuentesmemoria.fahce.unlp.edu.ar/art_revistas/pr. 2732/pr.2732.pdf, consultado el 5 de abril 2015.

Chaves, María Eugenia, María Chiquinquirá Díaz: una esclava del siglo XVIII: acerca de las identidades de amo y esclavo en el puerto colonial de Guayaquil, Archivo Histórico del Guayas, Guayaquil, 1998.

Chaves, María Eugenia, “La creación del 'Otro' colonial. Apuntes para un estudio de la diferencia en el proceso de la conquista americana y esclavización de los africanos" en Chaves, M. E. (ed.), Genealogías de la diferencia: tecnologías de la salvación y representación de los africanos esclavizados en Iberoamérica colonial, Editorial Pontificia Universidad Javeriana, Instituto de Estudios Sociales y Culturales Pensar, Abya-Yala, Bogotá, 2009, p. 178-243.

Clavero, Bartolomé, "La edad larga del derecho entre Europa y Ultramares”, Historia. Instituciones. Documentos, Sevilla, 1998, n²5, p. 135-150.

Clavero, Bartolomé, Historia del derecho: derecho común, Universidad de Salamanca, Salamanca, 1994.

Clavero, Bartolomé, "Delito y pecado. Noción y escala de transgresiones" en Sexo barroco y otras transgresiones premodernas, Alianza, Madrid, 1991, p. 57-89.

Clavero, Bartolomé, "Religión y derecho: mentalidades y paradigmas", Historia. Instituciones. Documentos, Sevilla, 1984, n¹1, p. 67-92.

Clavero, Bartolomé, “Almas y cuerpos. Sujetos de derecho en la Edad Moderna” en Annali della Facoltà di Giurisprudenza di Genova, Giuffrè Editore, Milán, 1990, p. 153-171. 
Crenshaw, Kimberlé, “Cartographie des marges: intersectionnalité politique de l'identité et violence contre les femmes de couleur”, Cahiers du genre, París, n³9, 2005, p. 51-82.

Davis, Ángela, "Violación, racismo y el mito del violador negro" en Mujeres, raza y clase, Akal, Madrid, 2005, p. 175-202.

Dellaferrera, Nelson, "La justicia penal eclesiástica en Córdoba del Tucumán durante el siglo XVIII" en Derecho y administración pública en las Indias hispánicas: actas del XII Congreso Internacional de Historia del Derecho indiano, Cortes de Castilla-La Mancha, Universidad de Castilla La Mancha, Toledo, 2002, vol. 1, p. 405-428.

Ducuara Nieto, Jeisson Alberto, “ 'La única libertad que tienen estos infelices es la de solicitar amo’. Esclavos y justicia en Ibagué 1750-1810”, Grafía, Bogotá, 2016, vol. 13, n², p. 29-47.

Duve, Thomas, "Algunas observaciones acerca del modus operandi y la prudencia del juez en el derecho canónico indiano", Revista de Historia del Derecho, Buenos Aires, 2007, n³5, p. 195-226.

Fernández Plastino, Alejandro, “Justicia colonial y esclavos en el Buenos Aires virreinal”, disponible en http://www.clacso.edu.ar/ libros/aladaa/fernan.rtf, consultado el 8 de septiembre de 2016.

Foucault Michel, La vida de los hombres infames, Altamira, La Plata, 1996.

Garriga Acosta, Carlos, “Justicia animada: dispositivos de la justicia en la monarquía católica”, Cuadernos de derecho judicial, Madrid, 2006, n6, p. 59-106.

Garriga Acosta, Carlos, "Sobre el gobierno de la justicia en Indias (Siglos XVI-XVII)", Revista de historia del derecho, Buenos Aires, 2006, n³4, p. 67-160

Garriga Acosta, Carlos \& Lorente Sariñena, Marta, "El juez y la ley: La motivación de las sentencias (Castilla, 1489 - España, 1855)”, Anuario de la Facultad de Derecho de la Universidad Autónoma de Madrid, Madrid, 1997, n¹, p. 97-144.

Goldberg, Marta, “La población negra y mulata de la ciudad de Buenos Aires, 1810-1840", Desarrollo Económico, Buenos Aires, 1976, vol. 16, n61, p. 75-99.

Goldberg, Marta, "La esclavitud negra: desde la esclavitud hasta los afrodescendientes actuales" en Hernán Otero (ed.), Historia de la provincia de Buenos Aires. Tomo I Población, ambiente y territorio, Unipe, Edhasa, Buenos Aires, 2012, p. 279-308.

Goldberg, Marta, “Mujer en la diáspora africana. Mujer negra rioplatense (1750-1840)”, Arenal, Granada, vol. 3, n¹, 1996, p. 115-131.

Goldberg, Marta, “Mujer negra rioplatense, 1750-1850" en Knecher, Lidia \& Panaia, Marta (coords.), La mitad del país. La mujer en la sociedad argentina de Buenos Aires, CEAL, Buenos Aires, 1994, p. 67-81.

González Undurraga, Carolina, "Los usos del honor por esclavos y esclavas: del cuerpo injuriado al cuerpo liberado (Chile, 1750-1823)", Nuevo Mundo Mundos Nuevos, Coloquios, n6, 2006, https:// journals.openedition.org/nuevomundo/2869, consultado el 10 de octubre de 2017.

González Undurraga, Carolina, Esclavos y esclavas demandando justicia. Chile, 1740-1823, Editorial Universitaria, Santiago de Chile, 2014.

Hering Torres, Max S., "Color, pureza, raza: la calidad de los sujetos coloniales" en Bonilla, Heraclio (ed.), La cuestión colonial, Universidad Nacional de Bogotá, 2011, p. 451-469.

Hespanha, António Manuel, La Gracia del Derecho. Economía de la Cultura en la Edad Moderna, Centro de Estudios Constitucionales, Madrid, 1993. 
Hunefeld, Christine, Mujeres, esclavitud, emociones y libertad. Lima, 1800-1854, Documento de Trabajo $n^{\circ} 24$, Instituto de Estudios Peruanos, Lima, 1988.

Kluger, Viviana, “¿Todo tiempo pasado fue mejor? La condición jurídica del esclavo a través de la mirada de los fiscales de la Audiencia de Buenos Aires (1785-1812)", Revista Jurídica Universidad Interamericana de Puerto Rico, 2003, San Juan, n³8, p. 93-123.

Lavallé, Bernard, “Cerros, angustias y espejismos: ser cimarrón en los valles trujillanos durante el siglo XVII" en Lavallé, Bernard, Amor y opresión en los Andes coloniales, Instituto Francés de Estudios Andinos, Universidad Ricardo Palma, Lima, 1999, p. 139-165.

Levaggi Abelardo, "La condición jurídica del esclavo en la época hispánica", Revista de Historia del Derecho, Buenos Aires, 1973, nº 1, p. 83-175.

Levaggi Abelardo, "La fundamentación de las sentencias en el Derecho Indiano", Revista de Historia del Derecho, Buenos Aires, 1978, n6, p. 45-73.

Lorandi, Ana María, Poder central, poder local. Funcionarios en el Tucumán colonial: un estudio de antropología política, Prometeo, Buenos Aires, 2008.

Lorente Sariñena, Marta (ed.), De justicia de jueces a justicia de leyes: hacia la España de 1870, Consejo General del Poder Judicial, Madrid, 2006.

Lorente Sariñena, Marta, “Justicia desconstitucionalizada: España, 1834-1868”, Cuadernos de derecho judicial, Madrid, 2006, $n^{\circ} 6$, p. 243-286.

Lucena Salmoral, Manuel, Regulación de la esclavitud negra en las colonias de América Española (1503-1886): Documentos para su estudio, Universidad de Alcalá, Universidad de Murcia, Murcia, 2005.

Lucena Salmoral, Manuel, Sangre sobre piel negra. La esclavitud quiteña en el contexto del reformismo borbónico, Abya Yala, Ecuador, 1994.

Lucena Salmoral, Manuel, Los códigos negros de la América Española, Ediciones Unesco, Universidad de Alcalá, Alcalá, 1996.

Lugones, María, “Colonialidad y género”, Tabula Rasa, n9, 2008, p. 73-101.

Lugones, María, “Colonialidad y género: hacia un feminismo descolonial” en Mignolo, Walter, (comp.), Género y descolonialidad, Ediciones del Signo, Buenos Aires, 2015, p. 13-42.

Mallo, Silvia, La Sociedad rioplatense ante la justicia: La transición del siglo XVIII al XIX, Archivo Histórico de la Provincia de Buenos Aires, ADAI, La Plata, 2004.

Mallo, Silvia, "La mujer rioplatense en el siglo XVIII", Anuario IEHS, Tandil, vol. V, 1990, p. 117132.

Mariluz Urquijo, José María, “La acción de sentenciar a través de los apuntes de Benito de la Mata Linares”, Revista de Historia del Derecho, Buenos Aires, 1976, n4, p. 141-159.

Moriconi, Miriam, "Usos de la justicia eclesiástica y de la justicia real (Santa Fe de la Vera Cruz, Río de la Plata, s. XVIII)", Nuevo Mundo, Mundos Nuevos, Debates, n¹2, 2012, disponible en http:// journals.openedition.org/nuevomundo/64359, consultado el 28 de octubre de 2012.

Moriconi, Miriam, "La administración de la justicia eclesiástica en el Río de la Plata, ss. XVIIXVIII: un horizonte historiográfico”, Historia da Historiografia, Río de Janeiro, 2013, n¹1, p. 210229. 
Moriconi, Miriam \& Barriera Darío G., "Las justicias en Santa Fe del Río de la Plata durante el período colonial (ss. XVI-XVIII)" en Silveira, Marco António \& Barral, María Elena (eds.), Historia, poder e instituciones. Diálogos entre Brasil y Argentina, Prohistoria, Rosario, 2015, p. 143-164.

Perri, Gladys, "Los esclavos frente a la justicia. Resistencia y adaptación en Buenos Aires, 1780-1830" en Fradkin, Raúl (ed.), 'La ley es tela de araña': ley, justicia y sociedad rural en Buenos Aires, 1780-1830, Prometeo, Buenos Aires, 2009, p. 51-81.

Perri, Gladys, “Algunas reflexiones en torno a la mano de obra rural bonaerense y el acceso a la justicia” en VVAA (ed.), Entre el Paraná y el Salado. Historia y regiones en el espacio bonaerense. Siglos XVIII a XX, UNLu, Luján, 2010, p. 67-78.

Prodi, Paolo, Una historia de la justicia. De la pluralidad de fueros al dualismo moderno entre conciencia y derecho, Katz, Buenos Aires, 2008.

Punta, Ana Inés, Córdoba borbónica: persistencias coloniales en tiempo de reformas (1750-1800), Universidad Nacional de Córdoba, Córdoba, 2009.

Rebagliati, Lucas, “¿Una esclavitud benigna? La historiografía sobre la naturaleza de la esclavitud rioplatense", Andes, Salta, 2014, vol. 25, n², Disponible en http://www.scielo.org.ar, consultado el 15 noviembre de 2016.

Rebagliati, Lucas, "Los pobres ante la justicia: discursos, prácticas y estrategias de subsistencia en Buenos Aires (1785-1821)", Boletín del Instituto de Historia Argentina y Americana Dr. Emilio Ravignani, Buenos Aires, 2013, n³8, p. 11-42.

Rufer, Mario, "Violencia, resistencia y regulación social de las prácticas: una aproximación a la esclavitud desde el expediente judicial. Córdoba, fines del siglo XVIII”, Cuadernos de Historia, Córdoba, 2001, n 4 , p. 195-230.

Saguier, Eduardo, "La crisis social. La fuga de esclava como resistencia rutinaria y cotidiana", Revista de Humanidades y Ciencias Sociales, Santa Cruz de la Sierra, 1995, vol. 1, n², p. 115-184, disponible en www.er-saguier.org, consultado el 5 de noviembre de 2016.

Santos, Francisco \& Amenzua, Luis, "La moderación de la pena en el caso de las personae miserabiles en el pensamiento jurídico hispano-americano de los siglos XVI y XVII", Revista de Historia del Derecho, Buenos Aires, 2013, n45, p. 245-264.

Schaub, Jean-Fréderic, Pour une histoire politique de la race, Seuil, Paris, 2015.

Scott, Joan, "El género: una categoría útil para el análisis histórico" en Amelang, James \& Nash, Mary (eds.), Historia y género: las mujeres en la Europa moderna y contemporánea, Alfons el Magnanim, Valencia, 1990, p. 23-56.

Segato, Rita, La crítica de la colonialidad en ocho ensayos. Y una antropología por demanda, Prometeo, Buenos Aires, 2013.

Tau Anzoátegui, Víctor, Casuismo y sistema. Indagación histórica sobre el espíritu del Derecho Indiano, Instituto de Investigaciones de Historia del Derecho, Buenos Aires, 1992.

Tau Anzoátegui, Víctor, “Acerca de la elaboración y publicación de la ley en el Derecho Indiano”, Anuario de Historia del Derecho, Madrid, 2010, vol. LXXX, p. 157-181.

Tell, Sonia, Córdoba rural: una sociedad campesina (1750-1850), Prometeo, Asociación Argentina de Historia Económica, Buenos Aires, 2008.

Thompson, Alvin O., Huida a la libertad. Fugitivos y cimarrones en el Caribe, Siglo XXI ediciones, Buenos Aires, 2005. 
Tovar Pinzón, Hermes, De una chispa se forma una hoguera: Esclavitud, insubordinación y liberación, Universidad Pedagógica y Tecnológica de Colombia, Tunja, 1992

Yangilevich, Melina, “Administración de justicia, derecho, gobierno y prácticas judiciales en la construcción estatal (Buenos Aires, 1821-1886)” en Elisa Caselli (coord.), Justicias, agentes y jurisdicciones. De la Monarquía Hispánica a los Estados Nacionales (España y América, siglos XVI-XIX), FCE, Madrid, 2016, p. 397-425.

Zúñiga, Jean Paul, “Morena me llaman.... Exclusión e integración de los afroamericanos en Hispanoamérica: el ejemplo de algunas regiones del antiguo virreinato del Perú" en Ares Queija, Berta \& Stella, Alessandro (eds.), Negros, mulatos, zambaigos: derroteros africanos en los mundos ibéricos, EEHA - CSIC, Sevilla, 2000, p. 105-122.

\section{NOTAS}

1. La principal y más sintética referencia es el Grupo HICOES (Historia Cultural e Institucional del Constitucionalismo en España y América). Sus producciones dialogan con las de otros representantes de esta corriente en Portugal, Francia e Italia y, además, informan sobre otras posiciones del campo iushistoriográfico sobre el mismo tema.

2. Para notar esta diferencia Marta Lorente explicó que con en la Declaración de Derechos del Hombre y del Ciudadano de 1789 se manifestó "uno de los cambios de paradigmas más significativos de la historia del Derecho occidental. Por ley, a partir de entonces, se va a poder entender exclusivamente el resultado de una decisión adoptada por una Asamblea de representantes elegidos por todos los ciudadanos; al mismo tiempo, a dicha decisión parlamentaria se le atribuirán una serie de caracteres de entre los que destacan su necesaria generalidad, su poder derogatorio y su siempre exigible publicidad". Lorente Sariñena, Marta, "Justicia desconstitucionalizada: España, 1834-1868", Cuadernos de derecho judicial, Madrid, 2006, $\mathrm{n}^{\circ} 6$, p. 243-286.

3. Garriga Acosta, Carlos, "Justicia animada: dispositivos de la justicia en la monarquía católica", Cuadernos de derecho judicial, Madrid, 2006, nº, p. 59-106.

4. Clavero, Bartolomé, Historia del derecho: derecho común, Universidad de Salamanca, Salamanca, 1994, p. 106.

5. 5 Clavero, B., Historia del derecho, Op. Cit., p. 106.

6. Garriga Acosta, C., "Justicia animada", Op. Cit. Tau Anzoátegui, Víctor, "Acerca de la elaboración y publicación de la ley en el Derecho Indiano", Anuario de Historia del Derecho Español, Madrid, vol. LXXX, 2010, p. 157-181.

7. Lorente Sariñena, M., "Justicia desconstitucionalizada", Op. Cit.

8. Además de las referencias bibliográficas que anteceden y siguen a esta, sobre la noción de persona en el Antiguo Régimen, diferenciada de la de sujeto humano individual y de la operación abstrayente del sujeto, sigo a Clavero, B. "Almas y cuerpos. Sujetos de derecho en la Edad Moderna” en Annali della Facoltà di Giurisprudenza di Genova, Giuffrè Editore, Milán, 1990, p. 153-171. De acuerdo con Clavero, el planteo hobbesiano de persona como sujeto de predicación del derecho, si bien anticipa intelectualmente la noción de persona jurídica en los términos que podemos comprenderla en un Estado de Derecho, tiene una recepción tardía por parte de la antropología jurídica europea continental y una adopción aún más retrasada que su recepción. De modo que, en el siglo XVIII, particularmente en la Monarquía Hispánica, el concepto de persona es aleatorio, cuando aparece resulta insustancial, respecto a nuestras nociones actuales. El Homo no parece existir como sujeto individualizado para el derecho. Y el concepto de Persona se encuentra transpersonalizado. Es decir, diversas cosas (un colectivo de individuos, inclusive) pueden aparecer como personas porque la persona no aparece como tal. Por otra parte, la 
mención del individuo se concibe como la "pluralidad de uno", aludiendo a unas condiciones (estamentales, religiosas, de género, de oficio, etc.) que en una situación o una serie de situaciones podían operar desdoblando o refundiendo la personalidad. Un ejemplo que ofrece el autor es el de las personae misserabiles, a quienes se consideran objeto de amparo, precisamente por "no tener el más mínimo viso de ser sujeto; bajo esta misma construcción llega a reservársele especial consideración a la mujer...” (p. 157-158). Clavero alerta específicamente sobre la distancia entre aquella noción de persona y los sentidos con los que puede figurarse en un Estado de Derecho. En la cita de referencia indaga qué tipo de unidad de fondo podía ofrecer el cuerpo físico en unos ordenamientos gestados bajo la preeminente valoración de: el alma en la definición del Homo (Homo est qui animam rationalem habet) y el cuerpo místico antes que la del cuerpo físico (Anima est plus quam corpus). Subraya asimismo que “...en lo que interesa al Derecho, se sitúa desde el principio aquí: en la situación, no en el individuo”. Es en la situación -en este caso en el espacio judicial- donde se activa el amparo al mismo tiempo que los principios de imputación (de pena, castigo y culpa). En situación judicial aparecen los sesgos de individuación, aunque la noción de persona no los contemple y aunque la contemplación del amparo judicial no sea conducente a su afirmación como sujeto ni como persona jurídica. De allí, que me interese por el caso de Teodora y en su potencial analítico situacional en estas condiciones de la cultura jurisdiccional del Río de la Plata, antes de la creación del Virreinato.

9. Agüero, Alejandro, "Formas de continuidad del orden jurídico. Algunas reflexiones a partir de la justicia criminal de Córdoba (Argentina), primera mitad del siglo XIX", Nuevo Mundo, Mundos Nuevos, Debates, $n^{\circ} 10,2010$, disponible en http://journals.openedition.org/nuevomundo/59352, p. 55, consultado el 13 de octubre 2017; Yangilevich, Melina, “Administración de justicia, derecho, gobierno y prácticas judiciales en la construcción estatal (Buenos Aires, 1821-1886)” en Elisa Caselli (coord.), Justicias, agentes y jurisdicciones. De la Monarquía Hispánica a los Estados Nacionales (España y América, siglos XVI-XIX), FCE, Madrid, 2016, p. 397-425; Barriera, Darío G., "Del gobierno de los jueces a la desjudicialización del gobierno. Desenredos en la trenza de la cultura jurisdiccional en el Río de la Plata (Santa Fe, 1780-1860)" en Slemian, Andréa \& Agüero, Alejandro \& Fernández de Sotelo, Rafael Diego (coords.), Jurisdicciones, Soberanías, Administraciones, Universidad Nacional de Córdoba, Córdoba (en prensa).

10. Clavero, B., “Almas y cuerpos”, Op. Cit. p. 169; Lorente Sariñena, M., “Justicia desconstitucionalizada", Op. Cit.

11. Mallo, Silvia, "La mujer rioplatense en el siglo XVIII", Anuario IEHS, Tandil, vol. V, 1990, p. 117-132; Goldberg, Marta, "La población negra y mulata de la ciudad de Buenos Aires, 1810-1840", Desarrollo Económico, vol. 16, №61, 1976, p. 75-99; Goldberg, Marta, "Mujer negra rioplatense, 1750-1850" en Knecher, Lidia \& Panaia, Marta (coords.), La mitad del país. La mujer en la sociedad argentina de Buenos Aires, CEAL, Buenos Aires, 1994, p. 67-81; Goldberg, Marta, "Mujer en la diáspora africana. Mujer negra rioplatense (1750-1840)", Arenal, Granada, vol. 3, nº 1, 1996, p. 115-131.

12. Remito a los artículos compilados en Lorente Sariñena, Marta (coord), De justicia de jueces a justicia de leyes: hacia la España de 1870, Consejo General del Poder Judicial, Madrid, 2006.

13. Por cuestiones de espacio no se cita al detalle la extensa bibliografía que puede relevarse en: Mallo, Silvia, La Sociedad rioplatense ante la justicia: la transición del siglo XVIII al XIX, Archivo Histórico de la Provincia de Buenos Aires, ADAI, La Plata, 2004; Barriera, Darío G., "Voces legas, letras de justicia. Culturas jurídicas de los legos en los lenguajes judiciales. (Río de la Plata, siglos XVI-XIX)" en Mantecón Tomás (ed.), Bajtin y la historia de la cultura popular: cuarenta años de debate, PubliCan, Santander, Universidad de Cantabria, 2008, p. 347-368; Perri, Gladys, "Los esclavos frente a la justicia. Resistencia y adaptación en Buenos Aires, 1780-1830" en Fradkin, Raúl (ed.), 'La ley es tela de araña: ley, justicia y sociedad rural en Buenos Aires, 1780-1830, Prometeo, Buenos Aires, 2009, p. 51-81; Rebagliati, Lucas, "Los pobres ante la justicia: discursos, prácticas y estrategias de 
subsistencia en Buenos Aires (1785-1821)", Boletín del Instituto de Historia Argentina y Americana Dr. Emilio Ravignani, Buenos Aires, $\mathrm{n}^{\circ} 38,2013$, p. 11-42.

14. Acerca de esta característica puede consultarse el clásico trabajo de Tau Anzoátegui, Víctor, Casuismo y sistema. Indagación histórica sobre el espíritu del Derecho Indiano, Buenos Aires, Instituto de Investigaciones de Historia del Derecho, 1992. Completan el sentido de este rasgo, entre otros, Mariluz Urquijo, José María, "La acción de sentenciar a través de los apuntes de Benito de la Mata Linares", Revista de Historia del Derecho, $\mathrm{n}^{\circ} 4$, 1976, p. 141-159; Levaggi, Abelardo, "La fundamentación de las sentencias en el Derecho Indiano", Revista de Historia del Derecho, Buenos Aires, n6, 1978, p. 45-73; Garriga Acosta, C., "Justicia animada”, Op. Cit.; Garriga Acosta, Carlos \& Lorente Sariñena, Marta, “El juez y la ley: La motivación de las sentencias (Castilla, 1489 - España, 1855)”, Anuario de la Facultad de Derecho de la Universidad Autónoma de Madrid, Madrid, 1997, n¹, p. 97-144; Duve, Thomas, "Algunas observaciones acerca del modus operandi y la prudencia del juez en el derecho canónico indiano", Revista de Historia del Derecho, Buenos Aires, n³5, 2007, p. 195-226; Agüero, Alejandro, "Ley penal y cultura jurisdiccional: a propósito de una Real Cédula sobre armas cortas y su aplicación en Córdoba del Tucumán, segunda mitad del siglo XVIII”, Revista de historia del derecho, Buenos Aires, n³5, 2007, p. 13-45.

15. Clavero Clavero, Bartolomé, "La edad larga del derecho entre Europa y Ultramares", Historia. Instituciones. Documentos, Sevilla, 1998, n²5, p. 135-150; Clavero, B., "Religión y derecho: mentalidades y paradigmas”, Historia. Instituciones. Documentos, Sevilla, n¹1, 1984, p. 67-92.

16. Hespanha, António Manuel, La Gracia del Derecho. Economía de la Cultura en la Edad Moderna, Centro de Estudios Constitucionales, Madrid, 1993; Clavero, B., Historia del derecho, Op. Cit.; Agüero, A., "Las categorías básicas de la cultura jurisdiccional” en Lorente Sariñena, M. (coord.), De la justicia de jueces, Op. Cit., p. 20-58.

17. Clavero, B., "La Edad Larga del Derecho", Op. Cit.; el autor consigna que el estado de esclavitud perdura "la negación más completa de la posibilidad de persona" (p. 140). Vuelve sobre el tema en la p. 145, donde en referencia a la población africana en América ratifica "traída bajo las condiciones de la negación más completa de posibilidad de persona". Si, como los indígenas, las personas esclavizadas, fueron objeto de protección, fue porque previamente se las había desposeído de la condición de sujeto, se las había incapacitado para disponer de ellas mismas.

18. Clavero, B., "Delito y pecado. Noción y escala de transgresiones" en Tomás y Valiente, Francisco \& Clavero, B. \& Hespanha, António Manuel \& Bermejo, José Luis \& Gacto, Enrique \& Álvarez Alonso, Clara, Sexo barroco y otras transgresiones premodernas, Alianza Editorial, Madrid, 1990, p. 57-89; Agüero, A., "Ley penal y cultura jurisdiccional”, Op. Cit.

19. Moriconi, Miriam, "La administración de la justicia eclesiástica en el Rio de la Plata, ss. XVIIXVIII: un horizonte historiográfico", Historia da Historiografia, Río de Janeiro, n¹1, 2013, p. 210-229.

20. La documentación alojada en el Archivo Histórico de la Arquidiócesis de Santa Fe de la Vera Cruz (AHASFVC) no está catalogada. He podido relevar la ocurrencia de las mujeres en este tribunal eclesiástico en diversos fondos (Querellas, Peticiones, Informes y testimonios, Autos y decretos). No todos los tomos de cada fondo poseen Índices, por lo cual una contabilización de estas intervenciones (180) solo es indicativa del estado de mi relevamiento para el siglo XVIII, tarea que aún no ha concluido. Por otra parte, en el fondo Inventarios constan listas de pleitos que, al menos en lo que llevo investigando en este archivo, no he podido localizar. Asimismo, debe tenerse en cuenta que no todas las "acciones judicialmente orientadas" -en los términos de Jorge Traslosheros- se formalizan en un expediente judicial.

21. Prefiero utilizar la noción de espacios conceptuales porque se trata de conceptos con una gran densidad teórica, abonados desde múltiples disciplinas y diferentes campos de estudio, con los cuales procederé a un uso categorial que no necesariamente supone adscribir a la totalidad de un campo ni a una sola teoría. 
22. El análisis de estas formas de dominación intersectadas trasciende el campo historiográfico y ha ocupado especialmente a las teóricas de la interseccionalidad. Puede verificarse diferentes usos del concepto de interseccionalidad en Crenshaw, Kimberlé, "Cartographie des marges: intersectionnalité politique de l'identité et violence contre les femmes de couleur", Cahiers du genre, París, n³9, 2005, p. 51-82; Davis, Ángela, "Violación, racismo y el mito del violador negro" en Mujeres, raza y clase, Akal, Madrid, 2005, p. 175-202; Bentouhami-Molino, Hourya, Race, cultures, identités. Une approche féministe et postcoloniale, PUF, París, 2015; Segato, Rita, La crítica de la colonialidad en ocho ensayos. Y una antropología por demanda, Prometeo, Buenos Aires, 2013; Lugones, María, “Colonialidad y género", Tabula Rasa, n9, 2008, p. 73-101; Lugones, M., “Colonialidad y género: hacia un feminismo descolonial" en Mignolo, Walter, (comp.) Género y descolonialidad, Ediciones del Signo, Buenos Aires, 2015, p. 13-42. Un balance minucioso sobre estas diferentes trayectorias del concepto en Estados Unidos, Europa y América Latina en Viveros, Mara, "La interseccionalidad: una aproximación situada a la dominación”, Debate Feminista, no52, 2016, p. 1-17.

23. Archivo Histórico de la Arquidiócesis de Santa Fe de la Vera Cruz (AHASFVC), Querellas, Libro (L) II, Santa Fe - Córdoba, 15 de abril de 1758 - 19 de junio de 1758, fojas (ff.) 141-144v.

24. En el siglo XVIII se estima que 1 legua medía, aproximadamente, 5,350 m. Cualitativamente, cuando los coetáneos refieren a 100 leguas se trata de una distancia cuyo recorrido a caballo o en caravanas de carretas, en las mejores condiciones climáticas de la zona bajo estudio, demandaba alrededor de una semana. Es difícil estimar con precisión el tiempo que insumió Teodora para recorrer esa distancia. En principio porque desconocemos si lo hizo a campo traviesa o se valió de algunos de los medios de transportes. Si se podría corroborar esta última posibilidad, tampoco facilitaría el cálculo, ya que las rutas terrestres se alargaban significativamente debido a las condiciones físicas del terreno y las condiciones de frontera de esa zona.

25. AHASFVC, Querellas, L II, Santa Fe, 15 de abril de 1758, f. 141r.

26. La referencia es a los trabajos de Gabriel Debien y Arlette Gautier citados en Thompson, Alvin O., Huida a la libertad. Fugitivos y cimarrones en el Caribe, Siglo XXI, Buenos Aires, 2005.

27. Entre otros, Chaves, María Eugenia, María Chiquinquirá Díaz: una esclava del siglo XVIII: acerca de las identidades de amo y esclavo en el puerto colonial de Guayaquil, Archivo Histórico del Guayas, Guayaquil, 1998; Hunefeld, Christine, Mujeres esclavitud, emociones y libertad. Lima, 1800-1854, Documento de Trabajo n²4, Instituto de Estudios Peruanos, Lima, 1988; González Undurraga, Carolina, "Los usos del honor por esclavos y esclavas: del cuerpo injuriado al cuerpo liberado (Chile, 1750-1823)", Nuevo Mundo Mundos Nuevos, Coloquios, n6, 2006, disponible en https:// journals.openedition.org/nuevomundo/2869, consultado el 10 de octubre de 2017; González Undurraga, Carolina, Esclavos y esclavas demandando justicia. Chile, 1740-1823, Editorial Universitaria, Santiago de Chile, 2014; Albert Batista, Celsa, Mujer y esclavitud en Santo Domingo, CEDEE, Santo Domingo, 1993.

28. La modalidad de cimarronaje individual en la que puede comprenderse el caso de Teodora, antes que encontrar ecos en las experiencias de los grandes palenques, tiene correspondencias en el análisis situacional del cimarronaje espontáneo, esporádico pero también individual, ofrecido en Lavallé, Bernard, “Cinco. Cerros, angustias y espejismos: ser cimarrón en los valles trujillanos durante el siglo XVII", en Amor y opresión en los Andes coloniales, Instituto Francés de Estudios Andinos, Universidad Ricardo Palma, Lima, 1999, p. 139-165.

29. Diccionario de Autoridades (1734) Tomo IV, Real Academia Española, disponible en http:// www.rae.es, consultado el 5 de noviembre de 2017.

30. Foucault, Michel, La vida de los hombres infames, Altamira, La Plata, 1996.

31. Aunque creo que huelga aclarar que la raza no existe, ni antropológica ni biológicamente, a pedido de les evaluadores amplío sobre este término. En primer lugar, evito pensar en términos esencialistas respecto de las asignaciones de identidades raciales. Me asiste la convicción sobre la importancia de estudiar los mecanismos profundos mediante los cuales individuos y grupos - en 
esta etapa, principalmente las mujeres fueron racializadas, pero también me guía la inquietud por conocer de qué modo una mujer podía invocar a su favor, unos atributos raciales impuestos. En consecuencia, abordo las prácticas eclesiásticas que investigo, como instancias constitutivas de los procesos de racialización, siendo la administración de justicia una de las instancias de recreación, reasignación y actualización de identidades raciales. En cuanto concierne específicamente a este artículo, y para no extenderme en una enumeración bibliográfica infinita, diré que "raza" es un término corrientemente empleado y aparece en la documentación base de mis investigaciones de los últimos años. Para circunscribir y diferenciar ese uso -cuyo significado puede consultarse en los tesoros lexicográficos de la Real Academia Española correspondientes al período analizado- agregaré que concibo a la raza -sin comillas- como uno de los dispositivos que, con base en la noción de "limpieza de sangre", criterios religiosos, lingüísticos, apreciaciones fenotípicas, diversa y situacionalmente articulados, produjo argumentos de superioridad e inferioridad, permitió establecer escalas pigmentocráticas e hizo posible la captura, esclavización y trata de personas de origen o ascendiente africano. Las consecuencias de esta política de racialización no solo reside en la generación de importantes réditos económicos para determinados grupos, sino también en la asignación de identidades, en las lesiones provocadas en los cuerpos y las subjetividades de las personas esclavizadas, con importantes resonancias en el presente. No obstante, debe tenerse en cuenta la larga historia del concepto "raza" y sus articulaciones con las políticas de racialización que afectaron a otras poblaciones (judías, indias, etc.) provocando múltiples procesos de minorización de individuos y grupos. Una exploración sobre las producciones eruditas y las connotaciones históricas del concepto articulada las formas de construcción de la diferencia, en Iberoamérica entre los siglos XVI a XVIII, en Chaves, María Eugenia, “La creación del 'Otro' colonial. Apuntes para un estudio de la diferencia en el proceso de la conquista americana y esclavización de los africanos”, en Chaves, M. E. (ed.), Genealogías de la diferencia: tecnologías de la salvación y representación de los africanos esclavizados en Iberoamérica colonial, Editorial Pontificia Universidad Javeriana, Instituto de Estudios Sociales y Culturales Pensar, Abya-Yala, Bogotá, 2009, p. 178-243; Hering Torres, Max S., "Color, pureza, raza: la calidad de los sujetos coloniales" en Bonilla, Heraclio (ed.), La cuestión colonial, Universidad Nacional de Bogotá, 2011, p. 451-469. En cuanto a su uso analítico y crítico remito a Schaub, Jean-Fréderic, Pour une histoire politique de la race, Seuil, Paris, 2015.

32. Remito al ya clásico artículo de Joan W. Scott, donde consigna que "el género es un elemento constitutivo de las relaciones sociales basadas en diferencias percibidas entre los sexos y (...) una manera primaria de significar relaciones de poder". (p. ) Además de describir los usos conceptuales y categoriales de "género", Scott afirmó que su práctica de historia del género, consistiría en señalar "los significados variables y contradictorios que se atribuyen a la diferencia sexual, a los procesos políticos por los cuales dichos significados se desarrollan y contradicen", en reparar en "la inestabilidad y maleabilidad de las categorías de 'mujer' y 'hombre', y a las formas en que estas categorías se articulan una respecto a la otra, aunque no sea de forma consistente ni igual cada vez" (p. 29). Entiende asimismo que la categoría género, no explica todas las desigualdades, ni todas las opresiones, ni toda la historia, pero ofrece otra posibilidad de analizar las dinámicas sociales y políticas que se evaporan en las explicaciones "universales". Pero fundamentalmente, remito al cierre de sus reflexiones donde vinculando investigación del pasado y compromiso con el presente, esta intelectual sugería "que el género debe redefinirse y reestructurarse en conjunción con una visión de igualdad política y social que comprende no sólo el sexo, sino también, la clase y la raza" (p. 56). Scott, Joan, "El género: una categoría útil para el análisis histórico" en Amelang, James \& Nash, Mary (eds.), Historia y género: las mujeres en la Europa moderna y contemporánea, Alfons el Magnanim, Valencia, 1990, p. 23-56.

33. Lucena Salmoral, M., Sangre sobre piel negra. La esclavitud quiteña en el contexto del reformismo borbónico, Abya Yala, Ecuador, 1994, p. 17. 
34. Lucena Salmoral, M., Regulación de la esclavitud negra en las colonias de América Española (1503-1886): Documentos para su estudio, Universidad de Alcalá, Universidad de Murcia, Murcia, 2005.

35. Lucena Salmoral, M., Los códigos negros de la América Española, Ediciones Unesco, Universidad de Alcalá, Alcalá, 1996. La posibilidad asumir la trata directa de esclavos africanos surgió en 1778, cuando Portugal, por el Tratado del Pardo (consecuencia del de Límites de 1777), cedió a España las islas africanas de Annobón y Fernando Poo, frente a la costa de Guinea, resultando ser el principal puente sin intermediarios para comerciar esclavos con destino a América.

36. “(...) en un terreno tan sensible como el conocimiento e invocación de la ley en las provincias indianas se percibe que el discurso jurídico -letrado o lego- era igualmente eficaz cuando se exponía un criterio jurídico o legal reconocido, sin necesidad de mencionar el texto legal, como exigirían luego los tiempos del positivismo. Esta actitud podría tanto interpretarse como un menor relieve del elemento legal, o como un recurso de necesidad ante el deficiente método de difusión de la ley. O ambos a la vez". Tau Anzoátegui, Víctor, “Acerca de la elaboración y publicación de la ley en el Derecho Indiano”, Anuario de Historia del Derecho Español, Madrid, vol. LXXX, 2010, p. 181.

37. Levaggi, Abelardo, "La condición jurídica del esclavo en la época hispánica", Revista de Historia del Derecho, Buenos Aires, n¹, 1973, p. 45-73. Algunas respuestas a las hipótesis del citado autor en Kluger, Viviana, “¿Todo tiempo pasado fue mejor? La condición jurídica del esclavo a través de la mirada de los fiscales de la Audiencia de Buenos Aires (1785-1812)”, Revista Jurídica Universidad Interamericana de Puerto Rico, San Juan, n³8, 2003, p. 93-123; Rebagliati, Lucas, “¿Una esclavitud benigna? La historiografía sobre la naturaleza de la esclavitud rioplatense”, Andes, Salta, vol. 25, $\mathrm{n}^{\circ} 2$, 2014, disponible en http://www.scielo.org.ar, consultado el 15 de noviembre de 2016; Perri, G., "Los esclavos frente a la justicia. Resistencia y adaptación en Buenos Aires, 1780-1830", Op. Cit. 38. AHSFVC, Querellas, L II, Santa Fe, 15 de abril de 1758, ff. 141-144v.

39. Archivo General de Indias (AGI), Indiferente General, Legajo (Leg.) 430, Libro (L) 42, Real Cédula de Carlos II a las Audiencias y gobernadores de las Indias. Buen Retiro, 12 octubre 1683, ff. 297v-298r.

40. Tovar Pinzón, Hermes, De una chispa se forma una hoguera: Esclavitud, insubordinación y liberación, Universidad Pedagógica y Tecnológica de Colombia, Tunja, 1992, p. 22. Citado en Lucena Salmoral, M., Regulación de la esclavitud negra en las colonias de América Española, Op. Cit., p. 101.

41. Entre otros, Saguier, Eduardo, "La crisis social. La fuga de esclava como resistencia rutinaria y cotidiana", Revista de Humanidades y Ciencias Sociales, Santa Cruz de la Sierra, vol. 1, n², 1995, p. 115-184. Disponible en www.er-saguier.org, consultado el 5 de noviembre de 2016; Zúñiga, Jean Paul, "Morena me llaman... Exclusión e integración de los afroamericanos en Hispanoamérica: el ejemplo de algunas regiones del antiguo virreinato del Perú" en Ares Queija, Berta \& Stella, Alessandro (comps.), Negros, mulatos, zambaigos: derroteros africanos en los mundos ibéricos, EEHA, CSIC, Sevilla, 2000, p. 105-122; Bernand, Carmen, Negros esclavos y libres en las ciudades Hispanoamericanas, Fundación Histórica Tavera, Madrid, 2001; Perri, G., "Los esclavos frente”, Op. Cit; Goldberg, M., "La esclavitud negra: desde la esclavitud hasta los afrodescendientes actuales", en Otero, Hernán (coord.), Historia de la provincia de Buenos Aires. Tomo I Población, ambiente y territorio, Unipe, Edhasa, Buenos Aires, 2012, p. 279-308; González Undurraga, Carolina, Esclavos y esclavas demandando justicia, Op. Cit.; Ducuara Nieto, Jeisson Alberto, “'La única libertad que tienen estos infelices es la de solicitar amo'. Esclavos y justicia en Ibagué 1750-1810”, Grafía, Bogotá, vol. 13, n², 2016, p. 29-47.

42. Con bases censales de 1778, Sonia Tell ha estimado una población de 6041 habitantes. Describe una zona de llanura, que alternaba cultivos y producción ganadera que fue desplazando la cría de mulas, por la vacuna y lanar. El porcentaje de fuerza de trabajo esclava (9,2 \%) era inferior al de los dependientes libres (14\%) y notablemente menor en relación a los 
independientes (76,8\%). La mayor cantidad de personas esclavizadas se concentraba en las unidades productivas más grandes. La historiadora también informa sobre la actuación de los jueces pedáneos. No he encontrado otras referencias sobre otros oficios de justicia secular o eclesiástica en el lugar, aun cuando, llamativamente, se utilizó la denominación "curato" para nombrar a los distritos jurisdiccionales cordobeses. Cfr. Tell, Sonia, Córdoba rural: una sociedad campesina (1750-1850), Córdoba, Prometeo, 2008.

43. De acuerdo con el corpus documental del análisis de Saguier, 384 registros notariales de Buenos Aires entre 1708-1819, "las mujeres esclavas procedentes del interior prácticamente no estaban representadas, pues sólo dos de ellas alcanzaron a quedar registradas como huidizas. Por el contrario, las mujeres esclavas prófugas procedentes de Buenos Aires en fuga hacia el interior fueron relativamente más numerosas, alcanzando como hemos visto antes, al $24 \%$ del total, 68 hembras sobre 305 varones. La fuga de las mujeres se concretaba a través de las flotas de carretas, convirtiéndose en volantonas, las actuales ruteras". Saguier, E., "La crisis social”, Op. Cit. Respecto al tratamiento de varones y mujeres esclavizados, en general: Rufer, Mario, "Violencia, resistencia y regulación social de las prácticas: una aproximación a la esclavitud desde el expediente judicial. Córdoba, fines del siglo XVIII", Cuadernos de Historia, Córdoba, nº 4 , 2001, p. 195-230; Agüero, A., "Ley penal y cultura jurisdiccional”, Op. Cit.; Agüero, A. Castigar y perdonar cuando conviene a la República. La justicia penal en Córdoba del Tucumán, siglos XVII y XVIII, Centro de Estudios Políticos y Constitucionales, Madrid, 2008.

44. Agüero, A., "Ley penal y cultura jurisdiccional”, Op. Cit.

45. Remito a mi más reciente referente en el tratamiento analítico de estas subjetividades Albornoz, María Eugenia, Experiencias de conflicto. Subjetividades, cuerpos y sentimientos en Chile, siglos XVIII y XIX, Acto editores, Santiago de Chile, 2015.

46. Levaggi, A., "La condición jurídica”, Op. Cit., p. 90.

47. Perri, Gladys, "Algunas reflexiones en torno a la mano de obra rural bonaerense y el acceso a la justicia” en VVAA (ed.), Entre el Paraná y el Salado. Historia y regiones en el espacio bonaerense. Siglos XVIII a XX, Universidad Nacional de Luján, Luján, 2010, p. 57.

48. "El mulato Antonio, la negra Isabel, la negra Juliana, el negro Juan Manuel, el negro Manuel, la negra Teresa y el negro Francisco fueron vendidos en 1787, 1790, 1795, 1804, 1812 y 1817 respectivamente, con la advertencia de haber huido en tres ocasiones distintas", en Saguier, E., "La crisis social", Op. Cit.

49. En otra investigación estoy trabajando las intervenciones en este sentido de las reinas Isabel de Farnesio y María Bárbara de Braganza.

50. Moriconi, Miriam \& Barriera, Darío G., "Las justicias en Santa Fe del Río de la Plata durante el período colonial (ss. XVI-XVIII)" en Silveira, Marco António \& Barral, María Elena (coords), Historia, poder e instituciones. Diálogos entre Brasil y Argentina, Prohistoria, Rosario, 2015, p. 143-164.

51. Para completar este marco consultar: Barriera, Darío G., "Justicias rurales: el oficio de alcalde de la hermandad entre el derecho, la historia y la historiografía (Santa Fe, gobernación del Río de la Plata, siglos XVII a XIX)", Andes, Salta, n²4, semestre 2013, p. 1-33; Barriera, Darío G. \& Forconi, María Celeste, "La compra de oficios como vía de acceso a las varas de justicia. Venalidad y coaliciones políticas en un cabildo rioplatense: la 'casa de los Monje' (Santa Fe, 1700-1750)", El Taller de la Historia, Cartagena de Indias, 2015, vol. 7, p. 255-305; Moriconi, Miriam, "Usos de la justicia eclesiástica y de la justicia real (Santa Fe de la Vera Cruz, Río de la Plata, s. XVIII)", Nuevo Mundo, Mundos Nuevos, Debates, $\mathrm{n}^{\circ} 12$, 2012, disponible en http://journals.openedition.org/ nuevomundo/64359, consultado el 28 de octubre de 2012.

52. Me consta, por la bibliografía citada, la vigencia del oficio de protector de esclavos en otros espacios, pero no en los archivos consultados en esta investigación.

53. González Undurraga, C., Esclavos y esclavas, Op. Cit.

54. Sobre su ejercicio en estas funciones AGSF, Actas de Cabildo, Tomo XII A, ff. 82 y siguientes. También consta su elección como alcalde de primer voto en el año 1770 y su solicitud para 
declinar el oficio por "sus achaques habituales", rechazada por el cuerpo capitular el 17 de enero de ese año, en AGSF, AC, Tomo XIV A, ff. 44-46.

55. AHASFVC, Querellas, L II, Santa Fe, de 1758, f. 141v.

56. AHASFVC, Querellas, L II, Santa Fe, de 1758, f. 141v.

57. AHASFVC, Querellas, L II, Santa Fe, de 1758, f. 141v.

58. AHASFVC, Querellas, L II, Santa Fe, de 1758, f. 142v.

59. Agüero, A., Castigar y perdonar, Op. Cit., p. 57-58 y 80-81.

60. AHSFVC, Querellas, L II, Córdoba, 23 de mayo de 1758, ff. 143-144.

61. Aspell, Marcela, "El Tribunal del Santo Oficio de la Inquisición en Córdoba del Tucumán", Ponencia presentada en el Congreso Internacional 'La Libertad Religiosa en el Siglo XXI. Religión, Estado y Sociedad', Facultad de Derecho y Ciencias Sociales, Universidad Nacional de Córdoba, Córdoba, 3-5 de septiembre de 2014. Disponible en www.calir.org.ar, consultado el 20 de noviembre de 2017.

62. Cfr. Prodi, Paolo, Una historia de la justicia. De la pluralidad de fueros al dualismo moderno entre conciencia y derecho, Katz, Buenos Aires, 2008; Turrini, Miriam, La coscienza e le leggi. Morale e diritto nei testi per la confessione della prima Età moderna, Il Mulino, Bologna, 1991, en especial p. 245-288.

63. Garriga Acosta, Carlos Antonio, "Sobre el gobierno de la justicia en Indias (Siglos XVI-XVII)", Revista de Historia del Derecho, Buenos Aires, no 34, 2006, p. 73.

64. Además de las tres censuras más conocidas -excomunión, entredicho y suspensión- las otras penas canónicas eran: deposición, degradación, infamia e irregularidad. Ver sus definiciones en: Directorio moral del R. P. Fr. Francisco Echarri por la Viuda de Joseph de Horga, Joseph Santiago Gómez, Murcia, 1770.

65. Dellaferrera, Nelson, "La justicia penal eclesiástica en Córdoba del Tucumán durante el siglo XVIII" en Derecho y administración pública en las Indias hispánicas: actas del XII Congreso Internacional de Historia del Derecho indiano, Cortes de Castilla-La Mancha, Universidad de Castilla-La Mancha, Toledo, 2002, vol. 1, p. 405-428.

66. Fue tan variante la cantidad de materias mixti fori, que los oficiales de justicia encontraron de gran utilidad los listados como el proporcionado, entre otros, por Francisco Ortiz de Salcedo en su Curia Eclesiástica de 1662; citado a menudo en los expedientes eclesiásticos.

67. Moriconi, M., "Usos de la justicia", Op. Cit.; Moriconi, Miriam, "Que parezca un disenso matrimonial... Regalismo borbónico, religión y mestizaje desde el prisma de la cultura jurisdiccional en el Río de la Plata (1787-1804)" en Barriera, Darío G. (coord.), Justicias situadas. Entre el Virreinato del Río de la Plata y la República Argentina, FaHCE, La Plata, 2018, p. 15-43.

68. Duve, Thomas, "Algunas observaciones acerca del modus operandi y la prudencia del juez en el derecho canónico indiano”, Revista de Historia del Derecho, Buenos Aires, n³5, 2007, p. 195-226; Santos, Francisco y Amenzua, Luis, "La moderación de la pena en el caso de las personae miserabiles en el pensamiento jurídico hispano-americano de los siglos XVI y XVII", Revista de Historia del Derecho, Buenos Aires, n45, 2013, p. 245-264.

69. "MISERABLE. adj. de una term. Desdichado, infelíz y desafortunado. Latín. Miserabilis. Miserandus". Diccionario de Autoridades (1734), Tomo IV, Real Academia Española, en http:// www.rae.es, consultado el 5 de noviembre de 2017.

70. En la literatura jurídica de la época, puede observarse la voluntad de una estricta, aunque a veces impracticable, delimitación de las causas mere y non mere eclesiásticas -las primeras, sobre materias espirituales, las segundas sobre causas temporales subordinadas a un fin espiritual- y de ambas respecto de las mere profanas o seculares, estrictamente temporales. Cfr. Curia Philipica de Juan de Hevia Bolaños, Tomo primero, Madrid 1761; Govierno eclesiastico-pacifico y union de los dos cuchillos Pontificio y Regio de Gaspar de Villarroel, 1738; Librería de jueces, utilísima y universal para toda clase de personas literatas y en especial para las que exercen la Jurisdicción Eclesiástica, Real y Mixta, 
Tomo II: En que por exposicion universal decisiva del Derecho canónico se explican sus titulos y leyes eclesiásticas de Manuel Silvestre Martínez, 1785, Madrid, 1791.

71. AHASFVC, Querellas, L. II, f. 144. El resaltado es mío.

72. AHASFVC, Querellas, L. II, f. 143.

73. Sobre los usos de la verdad en los juicios remito a Foucault, Michel, Microfísica del Poder, La Piqueta, Madrid, 1972; Farge, Arlette, La atracción del archivo, Alfons el Magnànim, Valencia, 1991. 74. AHASFVC, Querellas, L. II, f. 141v. El resaltado es mío.

75. Documento transcripto en Endrek, Emiliano, "El mestizaje en Córdoba. Siglo XVIII y principios del siglo XIX", Cuadernos de Historia de América, Córdoba, nXXXIII, 1966, p. 39-40, citado por Rufer, M., "Violencia, resistencia”, Op, Cit., p. 219-220 (no está consignada la Fuente). La fecha consignada por estos historiadores coincide con el período en que fue gobernador Juan Francisco de Pestaña y Chumaceno. Cfr. Lorandi, Ana María, Poder central, poder local. Funcionarios en el Tucumán colonial: un estudio de antropología política, Prometeo, Buenos Aires, 2008; Punta, Ana Inés, Córdoba borbónica: persistencias coloniales en tiempo de reformas (1750-1800), UNC, Córdoba, 2009. 76. La bibliografía de referencia sobre interseccionalidad de raza y género, consignada en la nota 20, trata específicamente sobre la larga práctica y la incidencia de la coerción y explotación sexual y la violación de amos a esclavas, ver entre otros, Davis, Á., Mujeres, raza, Op. Cit.; Bentouhami-Molino, H., Race, cultures, identités, Op. Cit., p. 69, 137-138. Desde el feminismo decolonial, esta filósofa, contribuye a repensar las distinciones entre público y privado en la constitución de los cuerpos políticos modernos y, más ejemplarmente, en la estrecha imbricación entre sexismo y racismo, racismo y sexualidad y, de modo más general, la imbricación histórica entre dominación y erotismo. Pero no se los plantea como simples binomios, sino de una compleja arquitectura de relaciones sociales y de subjetividades en varias dimensiones: por un lado, la sistemática violación de los amos a sus esclavas negras; por otro -en referencia a Franz Fanon- el carácter erótico del deseo de reconocimiento que incita al "hombre de color" a poseer a la "mujer blanca" y a la "mujer de color" a asociar la posibilidad de "blanqueamiento" a través del sexo con el hombre blanco. El "blanqueamiento", impuesto como norma de emancipación por parte de los varones dominantes también condicionó esa sexualidad racializada, al poner a disposición de las mujeres la vía más rápida: la sexualidad como mecanismo para emanciparse de la raza.

77. Rufer, M., “Violencia, resistencia”, Op. Cit., p. 220.

78. Utilizo esta expresión de uso corriente, utilizada también en Santa Fe y, más específicamente como alegato de un oficial de la Corona en juicio que analicé en "Sin nota de la mala raza. Una trama judicial en torno a las políticas borbónicas sobre matrimonios desiguales (Río de la Plata, 1787-1804)", ponencia presentada en el XIX Encuentro de Historia Regional Comparada (PIHSER), Universidad Nacional de Río Cuarto, Río Cuarto, Córdoba, Argentina, 1 y 2 de junio 2017. El expediente se encuentra en Archivo Histórico Provincial de Buenos Aires (AHPBA), 7-5-14-101. Real Audiencia, Disensos, Leg. 1, Santa Fe, 23 de junio de 1787- Buenos Aires, 20 de febrero de 1804.

79. El concepto de "castas" en los tesoros lexicográficos castellanos del siglo XVIII, conservó las connotaciones peyorativas de las acepciones medievales que lo asimilaban a un tipo de relación sexual bestial, es decir a una sexualidad animal, promiscua e irregular, y llevaba implícita en su significado la idea de ser heredera, no sólo del aspecto físico, sino de los vicios de sus ancestros africanos.

80. Mediante este recurso jurídico la o el comprador podía recuperar el precio pagado por un bien viciado, siempre y cuando dicho vicio se le hubiera ocultado expresamente. Si la redhibitoria se probaba el contrato quedaba sin efecto y se procedía a la devolución del dinero.

81. AHASFVC, Querellas, L II, Córdoba, 23 de mayo de 1758, f. 144.

82. Andrews, Reid, Los afroargentinos de Buenos Aires, Ediciones La Flor, Buenos Aires, 1989, p. 53; Levaggi, A., "La condición jurídica”, Op. Cit., p. 87. 
83. Bernand, Carmen, Negros esclavos y libres en las ciudades hispanoamericanas, Fundación Histórica Tavera, Madrid, 2001, p. 110-123.

84. Un estudio con base en juicios de Buenos Aires y su campaña consignó que el $35 \%$ de los fallos absolvían a los reos y "si bien esta decisión es acorde a la voluntad de los amos, la Justicia requiere de éstos el pago de los costes del proceso judicial y, eventualmente, una indemnización a la vindicta pública". Cfr. Fernández Plastino, Alejandro, "Justicia colonial y esclavos en el Buenos Aires virreinal", disponible en http://www.clacso.edu.ar/ libros/aladaa/fernan.rtf, consultado el 8 de septiembre de 2016.

85. Chakravorty Spivak, Gayatri, “¿Puede hablar el subalterno?”, Orbis Tertius, La Plata, 1998, vol. III, n6, p. 175-235, Disponible en: http://www.fuentesmemoria.fahce.unlp.edu.ar/art_revistas/ pr.2732/pr.2732.pdf, consultado el 5 de abril de 2015.

\section{RESÚMENES}

El artículo indaga en un expediente judicial labrado por la fuga de una mujer esclavizada y analiza la trama jurisdiccional del mismo. La estrategia metodológica que privilegia el microanálisis de un juicio se asienta en las condiciones del archivo, de las cuales resulta que no todos los documentos constituyen cabalmente expedientes judiciales, ni todos los expedientes judiciales exhiben el mismo recorrido, ni idéntica intervención de autoridades con potestad jurisdiccional. El tratamiento intensivo de la documentación judicial de un caso es metodológicamente afín al interés por examinar un sesgo colonial no siempre reconocido o suficientemente explícito en la historiografía jurisdiccionalista.

Based on a judicial file against a woman who escaped from slavery, this article analyzes its jurisdictional storyline. Methodologically, and given the possibilities offered by the archive, this study privileges a microhistorical approach to a singular case. Indeed, it turns out that neither all documents are properly judicial files, nor do all judicial records show the same course, and the intervention of jurisdictional authorities is not identical from one case to the next. An exhaustive analysis of a single judicial case is methodologically compatible with my interest for examining the colonial bias, not always recognized or sufficiently explicit in jurisdictional historiography.

Cet article analyse la trame juridictionnelle d'un dossier judiciaire contre une femme qui s'est échappée de sa condition d'esclave. D'un point de vue méthodologique, l'étude qui privilégie la micro-analyse d'un procès repose sur les conditions de l'archive. Il en résulte que tous les documents ne constituent pas des dossiers judiciaires; tous les dossiers judiciaires ne suivent pas la même trame, ni une intervention identique des autorités judiciaires. L'analyse exhaustive de la documentation judiciaire d'un seul cas est méthodologiquement compatible avec l'intérêt d'examiner un biais colonial qui n'est pas toujours reconnu ou suffisamment explicite dans l'historiographie judiciaire. 
ÍNDICE

Palabras claves: esclavos, fuga, cultura jurisdiccional, justicia eclesiástica, Río de la Plata, siglo XVIII

Keywords: slave fugitives, jurisdictional culture, ecclesiastical justice, Río de la Plata, 18th century

Mots-clés: esclave fugitif, culture juridictionnelle, justice ecclésiastique, Rio de la Plata, XVIIIe siècle

\section{AUTOR}

\section{MIRIAM MORICONI}

Doctora en Humanidades y Artes con mención en Historia. Docente investigadora, Universidad Nacional de Rosario. Profesora Titular de Historia Moderna, Universidad Autónoma de Entre Ríos. Miembro investigadora de Red Columnaria, Grupo Religio, Instituto de Historia Argentina y Americana “Dr. Emilio Ravignani”, Facultad de Filosofía y Letras, Universidad de Buenos Aires y del Centro de Historia Social, Universidad Nacional de Rosario. Rosario, Argentina. Este texto proviene del Proyecto "Hacer política en el espacio-tiempo de la modernidad: transgresiones y desobediencias en los siglos XVII y XVIII" (HUM574) SeCyT - UNR (2016-2017), el cual fue dirigido por la autora miriammoriconi[at]hotmail.com. 